\title{
Feedback of observed interannual vegetation change: a regional climate model analysis for the West African monsoon
}

\author{
Cornelia Klein ${ }^{1,2,4} \mathbb{D} \cdot$ Jan Bliefernicht $^{2} \cdot$ Dominikus Heinzeller $^{1} \cdot$ Ursula Gessner $^{3}$ • \\ Igor Klein $^{3} \cdot$ Harald Kunstmann ${ }^{1,2}$
}

Received: 27 November 2015 / Accepted: 12 June 2016 / Published online: 30 June 2016

(C) The Author(s) 2016. This article is published with open access at Springerlink.com

\begin{abstract}
West Africa is a hot spot region for land-atmosphere coupling where atmospheric conditions and convective rainfall can strongly depend on surface characteristics. To investigate the effect of natural interannual vegetation changes on the West African monsoon precipitation, we implement satellite-derived dynamical datasets for vegetation fraction (VF), albedo and leaf area index into the Weather Research and Forecasting model. Two sets of 4-member ensembles with dynamic and static land surface description are used to extract vegetation-related changes in the interannual difference between August-September 2009 and 2010. The observed vegetation patterns retain a significant long-term memory of preceding rainfall patterns of at least 2 months. The interannual vegetation changes exhibit the strongest effect on latent heat fluxes and associated surface temperatures. We find a decrease (increase) of rainy hours over regions with higher (lower) VF during the day and the opposite during the night. The probability that maximum precipitation is shifted to nighttime (daytime)
\end{abstract}

Cornelia Klein

cornkle@ceh.ac.uk

1 Karlsruhe Institute of Technology (KIT), Institute of Meteorology and Climate Research, Regional Climate and Hydrology, Kreuzeckbahnstr. 19, 82467 Garmisch-Partenkirchen, Germany

2 University of Augsburg, Institute of Geography, Regional Climate and Hydrology, Universitätsstr. 10, 86135 Augsburg, Germany

3 German Aerospace Center (DLR), German Remote Sensing Data Center (DFD), Münchner Strasse 20, 82234 Oberpfaffenhofen, Germany

4 Centre for Ecology and Hydrology (CEH), Maclean Building, Crowmarsh Gifford, Wallingford, Oxfordshire OX10 8BB, UK over higher (lower) VF is $12 \%$ higher than by chance. We attribute this behaviour to horizontal circulations driven by differential heating. Over more vegetated regions, the divergence of moist air together with lower sensible heat fluxes hinders the initiation of deep convection during the day. During the night, mature convective systems cause an increase in the number of rainy hours over these regions. We identify this feedback in both water- and energy-limited regions of West Africa. The inclusion of observed dynamical surface information improved the spatial distribution of modelled rainfall in the Sahel with respect to observations, illustrating the potential of satellite data as a boundary constraint for atmospheric models.

Keywords Land-atmosphere interaction · Vegetation feedback - West African monsoon · Precipitation - Satellite data

\section{Introduction}

In recent decades, the investigation of land-atmosphere interactions evolved into a focal point of research on West African monsoon (WAM) variability. From the vast number of studies that explored by which processes, under which conditions and by what magnitude the land surface might impact WAM rainfall, the picture emerged that land surface conditions, such as soil moisture, and particularly its heterogeneities (Taylor et al. 2011a) may significantly affect the initiation, maintenance and organisation of convective systems (see Xue et al. 2012, for a comprehensive review on recent studies). While teleconnections like sea surface temperatures and atmospheric oscillations mainly determine the overall WAM regime (e.g. Nicholson 2013), the land surface may modify, strengthen or buffer its state. 
Koster et al. (2004) identified regions of the world where strong gradients of soil moisture, vegetation and surface temperature prevail as especially prone to surface-atmosphere feedbacks. West Africa, and especially the semiarid Sahel, is such a transition zone between wet and dry regimes, where surface anomalies have the potential to affect the distribution of precipitation. Several studies propose different governing process chains that link soil moisture to precipitation depending on the spatio-temporal scale at focus (e.g. Taylor et al. 2011b, their Table 1). For example, mesoscale horizontal circulations induced by differential heating between wet and dry patches can generate moist updrafts that trigger deep convection (Anthes 1984; Wang and Eltahir 2000; Emori 1998). On local scales, the surface-specific partitioning of net radiation into latent (LH) and sensible heat $(\mathrm{SH})$ fluxes contributes to spatial variations in planetary boundary layer (PBL) growth (via $\mathrm{SH})$ and moistening (via LH) which sets the conditions for potential convection (Kohler et al. 2010). However, favourable surface and atmospheric conditions first have to coincide in order to produce a feedback. Therefore, the persistence of soil moisture patterns is an important factor for the probability that the atmosphere actually reaches a state that is sensible for surface conditions within the time that the surface anomaly prevails.

Eltahir (1998) points out that vegetation cover and soil moisture content play a similar role in the concept of land-atmosphere interactions. The important difference is that soil moisture anomaly patterns may only last for several days to weeks. Vegetation, on the other hand, is able to mobilize root zone soil moisture that would otherwise not be in contact with the atmosphere. Its anomaly patterns can last over weeks to months. It therefore imposes a lower boundary condition on the atmosphere that is effective over much longer time scales and furthermore reacts much slower on single precipitation events than surface soil moisture. Taylor (2008) suggests that such slow intra-seasonal modulations could be more important in the densely vegetated southern regions of West Africa as opposed to the barren Sahel, where the main response in latent heat fluxes is within a few days.

Several studies report a distinct sensitivity of WAM rainfall on vegetation changes at climatological time scales, where a positive vegetation-precipitation feedback dominates and results in an increased natural rainfall variability compared to cases without dynamic vegetation (e.g. Alo and Wang 2010; Kucharski et al. 2012; Zheng and Eltahir 1998). Besides natural land-cover changes, anthropogenic vegetation perturbations are another important factor that can lead to considerable vegetation changes over a few years. Taylor et al. (2002) used a land use model to generate land use change scenarios for the
Sahel between 1960 and 2015 that were implemented in a general circulation model (GCM) to quantify the combined impact of land use/land cover (LULC) change. The predicted increase of cropland by $9 \%$ and the loss of forest cover by $28 \%$ lead to a rainfall decrease of $9 \%$. Hagos et al. (2014) fed an estimation of the land degradation in the Sahel between 1950 and 2010 to the Weather Research and Forecasting model and likewise found a rainfall reduction. They attribute the decrease to a southward shift of the African Easterly Jet (AEJ) associated with a modification of the meridional moisture and temperature gradients by the LULC changes.

The often identified importance of vegetation variability on longer time scales raises the question whether this holds true for the interannual and seasonal scales, for which the quantitative vegetation changes are usually relatively small. Other than for soil moisture, the mechanisms by which vegetation patterns might directly affect the atmosphere and precipitation distribution are little discussed although such studies could benefit from satellite-derived information on vegetation changes nowadays available at very high spatial resolution (e.g. Hansen et al. 2013; Hollmann et al. 2013; Mayaux et al. 2004).

$\mathrm{Li}$ et al. (2007) used satellite-derived data at a rather coarse resolution of $1^{\circ}$ to investigate the influence of leaf area index and green vegetation fraction on the annual and interannual modulation of the WAM between 1987 and 1988 with a GCM at $\sim 300 \mathrm{~km}$ horizontal resolution. In accordance with mentioned climatological studies, they find a northward shift of the AEJ related to a modulation of the meridional temperature gradient. However, the coarse resolution in their study does not allow an investigation of vegetation impacts below the spatial scales of monsoon dynamics.

So far, the potential of implementing observed high-resolution surface information into a regional climate model for (1) model improvement in simulating the WAM and (2) identifying the processes by which natural interannual vegetation changes have an effect (if any) on the atmosphere has not been assessed for West Africa. We therefore use a new set of satellite-derived data for green vegetation fraction (VF), albedo (ALB) and leaf area index (LAI) at high spatial resolution to address the question how interannual changes of vegetation patterns may affect surface variables, atmospheric circulations and ultimately rainfall patterns at a local to regional scale. This surface data set has been recently generated specifically for the West African region including a novel high resolution land cover map.

The surface information is provided to the Weather Research and Forecasting (WRF, V. 3.61, Skamarock et al. 2008) model for the years 2009 and 2010 during the West African monsoon. A control simulation with a fixed 
climatological annual cycle for VF, ALB and LAI during both years is used to remove the large-scale signal from the interannual changes of surface and atmospheric variables.

Section 2 explains the specific model configuration and introduces the approach used to extract the surface signal. Section 3 presents the implemented dynamical surface datasets. Section 4 discusses the results for the vegetation impact on surface and atmospheric variables at large continental scales while Sect. 5 focuses on regional scales. Finally, the comparability to observations and other studies is discussed.

\section{Model and datasets}

\subsection{Analysis strategy}

Two WRF ensemble experiments, driven by ERA-Interim reanalysis data (ERA-I) (Dee et al. 2011), are conducted with (1) the observed state of surface variables (ALB, VF, LAI), that was derived from remote-sensing (DYN) and (2) default climatological datasets with a fixed annual cycle (CLIM) for the rainy seasons April-September 2009 and 2010, including four months of spin-up. The model analysis focuses on August-September, when vegetation anomalies reach their maximum (cf. Fig. 3). The two rainy seasons were simulated separately instead of conducting a continuous simulation in order to have the same integration time after the first soil moisture initialization for both years and to receive eight independent simulations per ensemble.

The two ensemble groups DYN and CLIM each consist of four members per year, for which the initial starting date is shifted by $0,-1,-2$ and -3 days. This approach is taken to account for the fact that a surface-driven atmospheric signal is not straightforward to extract. Given the chaotic character of convection, feedbacks on rainfall might or might not occur in response to a surface change. Therefore, if not otherwise indicated, all analyses use the average of the perturbed DYN and CLIM four-member ensembles in order to reduce the noise from internal model variability and thus to get a more robust signal of the mean changes related to the new dynamical surface dataset. We focus on the representation of the interannual difference $2010-2009(\Delta Y)$ for the dynamical DYN $\left(\Delta Y_{\text {Dyn }}\right)$ and the static CLIM $\left(\Delta \mathrm{Y}_{\text {Clim }}\right)$ surface case. The difference between the two ensembles then gives the impact of the dynamical land surface (Srfc):

$\Delta \mathrm{Y}_{\text {Srfc }}=\Delta \mathrm{Y}_{\text {Dyn }}-\Delta \mathrm{Y}_{\text {Clim }}$.

$\Delta \mathrm{Y}_{\text {Srfc }}$ represents a "vegetation-induced modulation of the large-scale driven changes" between 2009 and 2010. For example, for a temperature change from 25 to $30^{\circ} \mathrm{C}$ in CLIM and a change from 25 to $26^{\circ} \mathrm{C}$ in DYN, we obtain
$-4{ }^{\circ} \mathrm{C}$ for the vegetation signal $\Delta \mathrm{Y}_{\mathrm{Srfc}}$, which means that $\Delta \mathrm{Y}_{\text {Srfc }}$ can be negative although DYN exhibits an effective net warming.

The significance of $\Delta \mathrm{Y}_{\text {Srfc }}$ is given when the means of $\Delta \mathrm{Y}_{\text {Clim }}$ and $\Delta \mathrm{Y}_{\text {Dyn }}$ are significantly different from each other as estimated with a Student's $t$ test. The CLIM and DYN sample populations consist of 16 members each that arise from the 2010-2009 differences of all possible member combinations (the cartesian product of a 2010 and a 2009 vector). Note that the $\Delta Y_{\text {Srfc }}$ for the surface variables ALB, LAI and VF correspond to $\Delta \mathrm{Y}_{\text {Dyn }}$ since $\Delta \mathrm{Y}_{\mathrm{Clim}}$ is zero, resulting in

$\Delta \mathrm{Y}_{\mathrm{Srfc}}=\Delta \mathrm{Y}_{\text {Dyn }}$.

\subsection{Model set-up}

The WRF model domain encompasses the whole WAM region as can be seen in Fig. 1. If not indicated otherwise, all analyses are carried out for the domain $\left(9^{\circ} \mathrm{W}-9^{\circ} \mathrm{E}, 7-16^{\circ}\right.$ $\mathrm{N})$, focussing on the Sudanian zone $\left(7-12^{\circ} \mathrm{N}\right)$ and the Sahel $\left(12-16^{\circ} \mathrm{N}\right)$ to reduce effects from the ocean and the coastline.

The provided boundary conditions from ERA-I include sea surface temperatures and lateral atmospheric variables that are updated every $6 \mathrm{~h}$. In addition, soil moisture and soil temperatures are initialized from ERA-I for all simulations. The WRF model output is written at an hourly basis.

Different model configurations and their impact on the representation of the WAM dynamics were already investigated by Klein et al. (2015). On this basis, we run the WRF model with the RRTM/Dudhia Long and Shortwave Radiation schemes (Dudhia 1989), the LIN Microphysics scheme (Lin et al. 1983) and the YSU planetary boundary layer scheme (Hong et al. 2006). The YSU scheme is a firstorder closure scheme that also takes into account non-local vertical mixing in convective boundary layers by including a counter-gradient term in the vertical diffusion equation. The surface exchange coefficients are provided by the MM5 surface layer scheme based on the Monin-Obukhov similarity theory (Zhang and Anthes 1982), which is tied to the YSU scheme.

This parameterisation configuration reproduces the WAM without showing an extreme wet or dry behaviour. The horizontal resolution is $7 \mathrm{~km}$ without using a convective parameterisation to allow the model to explicitly resolve convection. An explicit treatment of convection is especially important for land-atmosphere interaction studies: the diurnal cycle of cloudiness and rainfall affecting the available energy at the surface (Marsham et al. 2013) and planetary boundary layer processes affecting atmospheric stability (Hohenegger et al. 2009) can realistically be represented with explicit convection but are not properly captured by current cumulus parameterisations. 


\subsection{The coupled land surface model}

The choice of the land surface model (LSM) is a critical point in assessing land-atmosphere interactions since it solves the surface energy balance

$\mathrm{R}_{\text {net }}=\mathrm{SW}_{\mathrm{in}}(1-\mathrm{ALB})+\mathrm{LW}_{\mathrm{in}}-\epsilon \sigma \mathrm{TS}^{4}=\mathrm{LH}+\mathrm{SH}+\mathrm{G}$,

where $\mathrm{SW}_{\text {in }}$ and $\mathrm{LW}_{\text {in }}$ are the incoming short-wave $\left(\mathrm{W} \mathrm{m}^{-2}\right)$ and long-wave radiation $\left(\mathrm{W} \mathrm{m}^{-2}\right)$ and $\epsilon, \sigma$ and TS are the surface emissivity, the Stefan-Boltzmann constant and the surface temperature $(\mathrm{K})$, respectively. The left-hand side of this equation represents the budget of incoming and outgoing solar radiation and provides the available net radiation $\mathrm{R}_{\text {net }}\left(\mathrm{W} \mathrm{m}^{-2}\right)$ at the ground. The net radiation is balanced by outgoing fluxes of latent heat $\left(\mathrm{LH}, \mathrm{W} \mathrm{m}^{-2}\right)$, sensible heat $\left(\mathrm{SH}, \mathrm{W} \mathrm{m}^{-2}\right)$ and the ground heat flux $\left(\mathrm{G}, \mathrm{W} \mathrm{m}^{-2}\right)$, whose partitioning strongly depends on the prevailing surface conditions. Hagos et al. (2014) investigated the uncertainty in modelled changes of surface flux partitioning and precipitation changes due to land use change in West Africa for three different LSM that are available in the WRF model. They found that an LSM that favoured a drier or wetter monsoon regime showed a lower sensitivity to land use changes in comparison to the intermediate case, since the evaporation from soils that are close to saturation or close to the wilting point does not vary significantly, even under land use change conditions. In their simulations, the Noah LSM showed an intermediate behaviour and the best performance with respect to observations for the modelled precipitation amounts and the meridional gradient of the evaporation fraction. We therefore apply the Noah LSM in our ensembles.

The atmospheric part of the WRF model forces the Noah LSM with atmospheric variables such as incoming long- and short-wave radiation, near surface temperature, pressure, humidity and precipitation. The Noah LSM then calculates the outgoing radiation with respect to ALB and TS of the previous time step and thus provides the radiative forcing $R_{\text {net }}$ at the ground (Eq. 2). Altogether, four variables are fed back to the atmosphere: (1) LH (evapotranspiration), (2) SH, (3) outgoing long-wave radiation (via calculation of TS) and (4) upward short-wave radiation (reflected portion given by surface albedo).

To derive $\mathrm{LH}$, the Penman potential evaporation $\mathrm{E}_{\mathrm{p}}$ ( $\mathrm{kg} \mathrm{m}^{-2} \mathrm{~s}^{-1}$, evaporation from an open water surface) is computed and adjusted according to the bare and vegetated portion of a model grid cell, which is determined by the green vegetation fraction, VF. The actual evapotranspiration is the sum of the partial fluxes for direct evaporation $E_{\text {dir }}\left(\mathrm{kg} \mathrm{m}^{-2} \mathrm{~s}^{-1}\right)$ from soil and the total plant transpiration $E_{t}\left(\mathrm{~kg} \mathrm{~m}^{-2} \mathrm{~s}^{-1}\right)$ (evaporation from canopy and snow sublimation are neglected in this example) that are defined as
$\mathrm{E}_{\mathrm{dir}}=(1-\mathrm{VF}) \beta \mathrm{E}_{\mathrm{p}}$

and

$\mathrm{E}_{\mathrm{t}}=\operatorname{VF} \mathrm{E}_{\mathrm{p}} \mathrm{P}_{\mathrm{c}}\left(1-\left(\frac{\mathrm{W}_{\mathrm{c}}}{\mathrm{S}}\right)^{0.5}\right)$,

where $\mathrm{W}_{\mathrm{c}}$ is the amount of water intercepted by the canopy and $\mathrm{S}$ is the maximum water capacity of the canopy (set to $0.5 \mathrm{~mm}$ ). In these equations, $\beta$ and $\mathrm{P}_{\mathrm{c}}$ represent resistance factors that act to reduce $\mathrm{E}_{\mathrm{p}}$. Both take into account the soil hydraulic properties and corresponding soil moisture availability but the plant coefficient $\mathrm{P}_{\mathrm{c}}$ additionally includes plant type and root depth, the influence of heat stress, the water vapour deficit and incoming solar radiation and therefore incorporates the canopy resistance. In this framework, LAI is used to upscale the parameters incorporated in $\mathrm{P}_{\mathrm{c}}$ that represent leaf stress (due to solar radiation, humidity, soil moisture, air temperature) to the entire canopy, where a higher LAI results in a lower canopy resistance (see Chen and Dudhia 2001, for a detailed description). Consequently, $E_{t}$ depends on the soil moisture conditions within the root zone while for bare soil, $\mathrm{E}_{\mathrm{dir}}$ is simply a function of relative soil moisture availability in the first soil layer. The new surface temperature TS is computed iteratively in a linear approach and arises from the surface energy balance equation in the form of

$\mathrm{TS}=\frac{\mathrm{R}_{\mathrm{net}}-\mathrm{LH}-\mathrm{G}}{\rho \mathrm{C}_{\mathrm{p}} \mathrm{C}_{\mathrm{h}} \mathrm{U}}+\Theta_{\text {air }}$.

Here, $\mathrm{SH}$ is implicitly contained as

$\mathrm{SH}=\rho \mathrm{C}_{\mathrm{p}} \mathrm{C}_{\mathrm{h}} \mathrm{U}\left(\mathrm{TS}-\Theta_{\text {air }}\right)$,

where $\rho$ is the air densitiy $\left(\mathrm{kg} \mathrm{m}^{-3}\right), \mathrm{C}_{\mathrm{p}}$ is the heat capacity of dry air $\left(\mathrm{J} \mathrm{m}^{-3} \mathrm{~K}^{-1}\right), \mathrm{C}_{\mathrm{h}}$ is the surface exchange coefficient, $\mathrm{U}$ is the wind speed $\left(\mathrm{m} \mathrm{s}^{-1}\right)$ and $\Theta_{\text {air }}$ is the potential air temperature $(\mathrm{K})$.

This summary of variable dependencies describes how state variables and surface fluxes directly react on changes in ALB, VF or LAI: ALB has a direct effect on $R_{\text {net }}$ and therefore impacts the available energy for the turbulent surface fluxes. VF is the key parameter for the partitioning between bare soil evaporation and plant transpiration. The efficiency of the latter, and therefore the actual difference between bare soil evaporation and plant transpiration, is modified by the canopy resistance and thus by LAI. However, in this study the objective is not to disentangle the separate effects of these intrinsically connected surface parameters, but to investigate whether their "bulk effect" leaves an imprint on the atmosphere. As an approximation, we therefore use VF changes as a proxy for associated changes of all three variables in our feedback analyses. 
Table 1 Land surface datasets for albedo (ALB), green vegetation fraction (VF) and leaf area index (LAI) used in the WRF model: dynamical datasets for the region $\left(9^{\circ} \mathrm{W}-10^{\circ} \mathrm{E} ; 4-16^{\circ} \mathrm{N}\right)(\mathrm{DYN})$, dynamical global datasets (GLOB) and the global default WRF climatology datasets (CLIM)

\begin{tabular}{llllll}
\hline Name & Time step & Resolution & Time period & Source & Reference \\
\hline DYN & & & & & \\
ALB $_{\text {Dyn }}$ & Monthly & $\sim 1 \mathrm{~km}$ & $2000-2014$ & MCD43B3 & LP DAAC (2014) \\
VF $_{\text {Dyn }}$ & 10 -daily & $\sim 1 \mathrm{~km}$ & $2007-2012$ & SEVIRI/SPOT_VGT & Camacho and Cernicharo (2015) and Gessner et al. (2013) \\
LAI $_{\text {Dyn }}$ & 10 -daily & $\sim 1 \mathrm{~km}$ & $2007-2012$ & SEVIRI/SPOT_VGT & Camacho and Cernicharo (2015) and Gessner et al. (2013) \\
GLOB & & & & & \\
ALB $_{\text {Glob }}$ & 10 -daily & $\sim 1 \mathrm{~km}$ & $1999-2015$ & SPOT_VGT & Camacho and Sánchez (2015) \\
VF $_{\text {Glob }}$ & 10 -daily & $\sim 1 \mathrm{~km}$ & $1999-2015$ & SPOT_VGT & Camacho and Cernicharo (2015) \\
LAI $_{\text {Glob }}$ & 10 -daily & $\sim 1 \mathrm{~km}$ & $1999-2015$ & SPOT_VGT & Camacho and Cernicharo (2015) \\
CLIM & & & & & \\
ALB $_{\text {Clim }}$ & Monthly & $\sim 17 \mathrm{~km}$ & $1985-1991$ & AVHRR & Csiszar and Gutman (1999) \\
VF $_{\text {Clim }}$ & Monthly & $\sim 17 \mathrm{~km}$ & $1985-1991$ & AVHRR & Gutman and Ignatov (1998) \\
LAI $_{\text {Clim }}$ & Monthly & $\sim 3 \mathrm{~km}$ & $2001-2010$ & MODIS & Kumar et al. (2014) \\
\hline
\end{tabular}

\subsection{Reference datasets}

The model simulations are compared to different satellite, observational and reanalysis data to evaluate their capability to capture the monsoon regime and interannual differences between 2009 and 2010 .

For precipitation, the NASA Tropical Rainfall Measuring Mission (TRMM) $0.25^{\circ}$ resolution 3B42V7 rainfall estimates (Huffman et al. 1995, 1997), the African Rainfall Estimate version 2 (RFE) (NOAA CPC 2013) $0.1^{\circ}$ combined satellite-gauge data product and the $0.25^{\circ}$ resolution daily global CMORPH (CPC Morphing technique, Joyce et al. 2004) are used. All three datasets are available at daily resolution.

Model surface temperatures are compared to the Global Historical Climatology Network (GHCN) $5^{\circ}$ gridded temperature product Version 3 (Lawrimore et al. 2011), the University of Delaware $0.5^{\circ}$ station-analysis product (Legates and Willmott 1990) and the station-data based Climatic Research Unit (CRU) TS3.21 $0.5^{\circ}$ product (Harris et al. 2013). All three datasets come at monthly resolution.

Due to the small amount of available flux tower data in West Africa, the information on surface fluxes is probably the most uncertain. The only available gridded product for latent and sensible heat fluxes is the FLUXNET Multi-Tree Ensemble (MTE) at $0.5^{\circ}$ (Jung et al. 2011) on a monthly basis. Additionally, we use two reanalysis-based products ERA Interim/LAND (Balsamo et al. 2015; Albergel et al. 2013) and MERRA-Land (Reichle et al. 2011) at monthly resolution. Both products are land-only reanalysis products from off-line simulations with updated land surface models and a new merged precipitation forcing from gauge data and reanalyses. Monthly soil moisture estimates are taken from the $0.5^{\circ}$ gridded CPC soil moisture (V2) dataset (Van
Den Dool et al. 2003). The monsoon dynamics are compared to ERA-I data. If not indicated otherwise, all data, including WRF, is transformed (averaged) to temporally and spatially match the coarsest available resolution of the considered datasets for each individual analysis.

\section{The dynamical land-surface parameters}

In order to represent spatio-temporal land surface changes in the WRF model, new dynamical land-surface parameters for ALB, VF and LAI (DYN) are integrated to replace the default monthly climatological datasets (CLIM). The CLIM datasets represent five to ten year climatologies from the Moderate Resolution Imaging Spectroradiometer (MODIS) and the Advanced Very High Resolution Radiometer (AVHRR). All used surface parameter datasets are summarised in Table 1, including references for further details regarding their generation.

\subsection{Generation and implementation of the dynamical datasets}

The $\mathrm{LAI}_{\text {Dyn }}$ and $\mathrm{VF}_{\text {Dyn }}$ time series were created by fusing LAI and VF datasets derived from data of the Spinning Enhanced Visible and Infrared Imager (SEVIRI; LSA SAF 2013) and Satellite Pour l'Observation de la Terre-VEGETATION (SPOT_VGT; Baret and Weiss 2010, 2014; Camacho and Cernicharo 2015). The SPOT_VGT-based datasets provide good quality information on LAI and VF in 10-day intervals at $1 \mathrm{~km}$ spatial resolution, but show frequent cloud gaps during the rainy season, while the SEVIRI-based daily datasets exhibit fewer cloud gaps but at a coarser spatial resolution of $3 \mathrm{~km}$ (Camacho and Cernicharo 2015; Gessner 
et al. 2013). Both datasets were aggregated to a spatio-temporal resolution of $1 \mathrm{~km}$ and 10-daily intervals. The SEVIRI datasets were matched to SPOT_VGT values based on slope and offset of three linear regressions fitted for gap unaffected areas and three seasons (Jan-Mar, Apr-Sep and OctDec). Finally, the cloud gaps in the SPOT_VGT products were filled with the adapted SEVIRI-based LAI and VF values. Remaining outliers in the time series were removed and remaining gaps were filled by temporal linear interpolation.

The $\mathrm{ALB}_{\text {Dyn }}$ time series is based on the bi-hemispherical reflectance (white-sky albedo) for the shortwave spectral range of the MODIS MCD43B3 product (LP DAAC 2014). The MCD43B3 is a composite product based on 16-day intervals at $1 \mathrm{~km}$ spatial resolution. Like for LAI and VF, the product features gaps, especially during the wet season. To generate a gap free input, we aggregated the products to monthly composites by calculating the mean of corresponding months. The remaining data gaps were filled with long-term monthly mean values (15 years: 2000-2014). Finally, the time series underwent temporal smoothing using the Savitzky-Golay filter (William et al. 1992).

The DYN datasets for ALB, VF and LAI only span the focus study region $9^{\circ} \mathrm{W}-9^{\circ} \mathrm{E}, 4-16^{\circ} \mathrm{N}$. In the rest of the WRF domain, global datasets (GLOB, cf. Table 1) are used to provide dynamical surface information. Remaining gaps due to cloud cover in GLOB are filled with the GLOB long-term mean value for the respective pixel and month.

All datasets shown in Table 1 are linearly interpolated to 6-h timesteps. They act as boundary condition for the WRF model and are updated every $6 \mathrm{~h}$. Spatially, the datasets are interpolated (coarser datasets) or regridded and averaged (finer datasets) to the model grid at $7 \mathrm{~km}$ resolution. While the averaging implies a loss of information for LAI, it preserves a proper grid-scale representation of the variables affected by VF and ALB (Kunstmann 2008).

Other necessary land surface parameters (e.g. surface roughness, root zone depth) rely on table values that are associated with a certain land use classification. Therefore, a regionally optimized land use classification (DLC) map at $250 \mathrm{~m}$ spatial resolution, based on the year 2006 (Gessner et al. 2015), is additionally implemented in the model in order to ensure consistency of the assigned table values with the new DYN datasets. Figure $1 \mathrm{~b}$ shows the $7 \mathrm{~km}$ upscaled maps of DLC and the WRF default $1 \mathrm{~km}$ MODIS land classification map based on 2002 (MLC, Friedl et al. 2010). The $7 \mathrm{~km}$ upscaled DLC and MLC consider the dominating land class only.

\subsection{Comparison of dynamical and climatological datasets}

There is a considerable albedo offset between DYN and CLIM, illustrated in Fig. 2, with a mean deviation of $2.4 \%$ in the Sahel and $1.9 \%$ in the Sudanian zone, which arises because $A^{2} B_{\text {Dyn }}$ is based on MODIS shortwave broadband white-sky albedo, while $\mathrm{ALB}_{\mathrm{Clim}}$ represents AVHRR clear-sky albedo. This offset and its physical effects hinders a direct comparison of the DYN and CLIM simulations. Instead, we compare the interannual change of the respective simulation case (cf. Sect. 2.1), assuming that for $\Delta \mathrm{Y}$, the effect of this offset is negligible.

Differences between $\mathrm{VF}_{\text {Dyn }}$, $\mathrm{LAI}_{\text {Dyn }}$ and the climatological dataset are smaller, but show pronounced higher maxima during the rainy season. As expected, the standard deviations are generally higher for the DYN datesets compared to the climatological annual cycles.

\subsection{Consistency of the dynamical datasets}

The DYN monthly anomalies for the Sahel in Fig. 3a show good agreement with each other as well as with observed precipitation ( $\mathrm{PCP})$ and soil moisture estimates (SM), giving confidence in their quality. $\mathrm{LAI}_{\text {Dyn }}$ co-varies with the $\mathrm{VF}_{\text {Dyn }}$ anomalies and is therefore not shown. In the Sahel, $\mathrm{SM}$ and $\mathrm{VF}_{\mathrm{Dyn}}$ anomalies show maximum correlations with PCP anomalies of 0.71 and 0.74 with a lag of one month, as shown in Fig. 4. Even after two months, the correlations do not drop below 0.55. In contrast, Lohou et al. (2014) identified an immediate increase of the evaporative fraction at flux station sites in Niger and Mali with a recovery time to its original state of only 1-3 days. This illustrates that in the Sahel, changes in vegetation cover after rainfall events are much slower but longer lasting than changes in surface soil moisture.

In the generally moister and more densely vegetated Sudanian zone, VF reacts with a smaller temporal lag to PCP anomalies shown by similar correlations for a lag of 0 and 1 month. However, corresponding to Camberlin et al. (2007), vegetation changes are generally less sensitive to PCP anomalies $(\mathrm{r} \sim 0.47)$ since water availability is a weaker constraint in this region than in the Sahel.

Nevertheless, this illustrates that vegetation may retain a long-term memory of preceding rainfall anomalies over the whole region. We hypothesize that surface patterns that were induced by precipitation in the early months of the rainy season may affect the patterns of rainfall in the late rainy season. We therefore focus on the period from August to September (Aug-Sep), when vegetation anomalies reach their maximum (cf. Fig. 3) and the error that is introduced by climatological datasets should be largest.

The years 2009 and 2010 show a transition from a negative $(-4.6 \%)$ to a positive (4\%) VF anomaly in the Sahel and are therefore suitable to assess the potential contribution of the changing land surface to this transition as compared to a climatological case. The regional patterns of $\Delta Y_{\text {Dyn }}$ in Fig. 5 show that differences in VF locally reach 
Table 2 Area-averaged total values for DYN and CLIM and their bias with respect to the mean values obtained from the reference datasets (REF) for precipitation (PCP, mm month ${ }^{-1}$ : TRMM, RFE, $\mathrm{CMORPH}$ ), surface temperature (TS, ${ }^{\circ} \mathrm{C}$ : GHCN, UDEL, CRU) and latent $(\mathrm{LH})$ and sensible heat flux $(\mathrm{SH})\left(\mathrm{W} \mathrm{m}^{-2}\right.$ : MTE, ERA Interim/ LAND, MERRA-Land) for the box $\left(9^{\circ} \mathrm{W}-9^{\circ} \mathrm{E} ; 7-16^{\circ} \mathrm{N}\right) . \Delta \mathrm{Y}$ is the respective interannual difference (2010-2009)

\begin{tabular}{|c|c|c|c|c|c|c|c|c|c|c|c|c|}
\hline & \multicolumn{3}{|l|}{ PCP } & \multicolumn{3}{|l|}{$\mathrm{TS}$} & \multicolumn{3}{|l|}{ LH } & \multicolumn{3}{|l|}{$\mathrm{SH}$} \\
\hline & REF & DYN & CLIM & REF & DYN & CLIM & REF & DYN & CLIM & REF & DYN & CLIM \\
\hline \multicolumn{13}{|l|}{ Total } \\
\hline 2009 & 174.8 & 170.1 & 183.2 & 27.1 & 27.0 & 27.5 & 81.8 & 81.8 & 78.0 & 37.0 & 59.3 & 65.2 \\
\hline 2010 & 192.4 & 188.7 & 200.5 & 26.7 & 26.5 & 27.1 & 83.2 & 84.0 & 77.9 & 34.5 & 52.0 & 58.0 \\
\hline$\Delta \mathrm{Y}$ & 17.6 & 18.6 & 17.3 & -0.4 & -0.5 & -0.4 & 1.4 & 2.2 & -0.1 & -2.5 & -7.3 & -7.2 \\
\hline \multicolumn{13}{|l|}{ Bias } \\
\hline 2009 & 174.8 & -4.7 & 8.4 & 27.1 & -0.1 & 0.4 & 81.8 & 0 & -3.7 & 37.0 & 22.3 & 28.2 \\
\hline 2010 & 192.4 & -3.7 & 8.1 & 26.7 & -0.2 & 0.4 & 83.2 & 0.8 & -5.2 & 34.5 & 17.5 & 23.5 \\
\hline$\Delta \mathrm{Y}$ & 17.6 & 1 & -0.3 & -0.4 & -0.1 & 0 & 1.4 & 0.8 & -1.5 & -2.5 & -4.8 & -4.7 \\
\hline
\end{tabular}

(a)

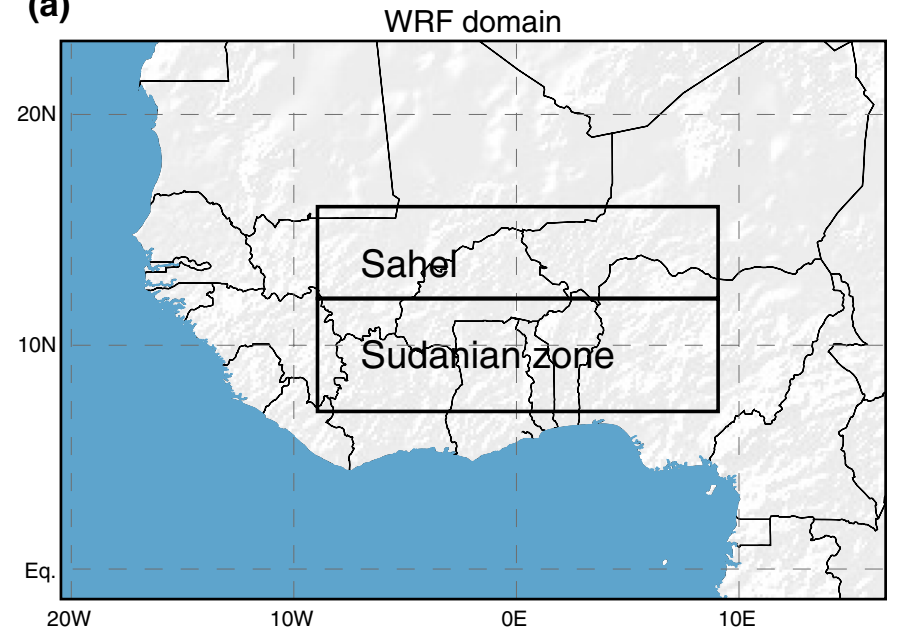

Water

Barren or Sparsely Vegetated

Snow and Ice

Cropland/natural vegetation mosaic

Urban and Built-Up

Croplands

Permanent wetlands

Grasslands

Savannas

Woody Savannas

Open Shrublands

Closed Shrublands

Mixed Forests

Deciduous Broadleaf Forest

Deciduous Needleleaf Forest

Evergreen Broadleaf Forest

Evergreen Needleleaf Forest

(b)

DLC

MLC

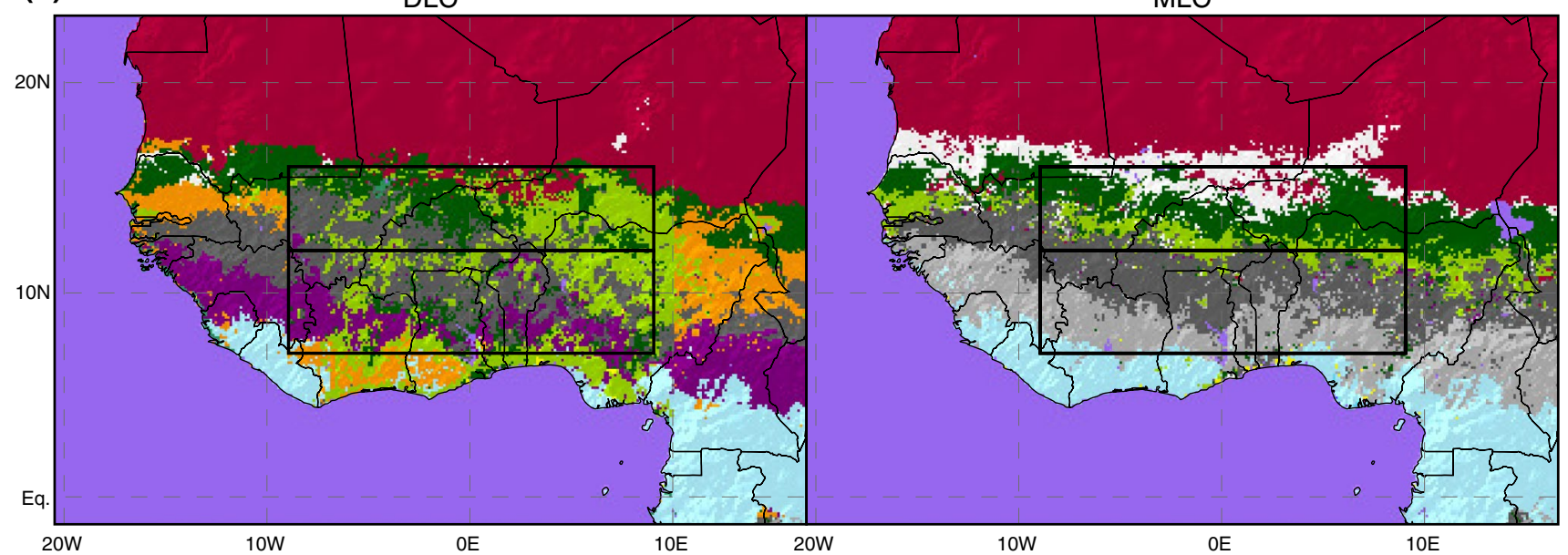

Fig. 1 a WRF domain with indicated study region $\left(9^{\circ} \mathrm{W}-9^{\circ} \mathrm{E}, 7-16^{\circ}\right.$ $\mathrm{N})$ and the sub-regions including the Sudanian zone $\left(7-12^{\circ} \mathrm{N}\right)$ and the Sahel $\left(12-16^{\circ} \mathrm{N}\right)$, b Left regionally optimized land use classifi- cation (DLC) for the simulations with dynamical surface parameters (DYN), right MODIS land use classes (MLC) for the WRF default case (CLIM) 
(a)

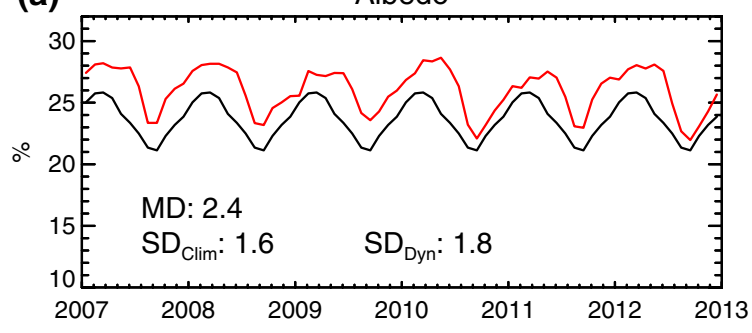

Green Vegetation Fraction
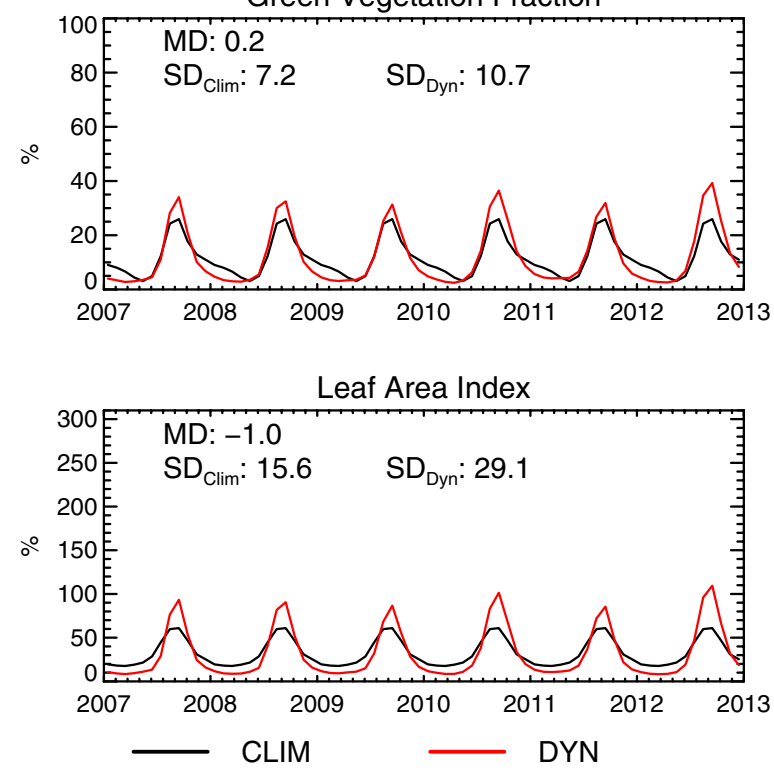

Fig. 2 Annual cycles of the dynamical datasets (DYN) in comparison to WRF default climatologies (CLIM) in (a) the Sahel and (b) the Sudanian zone for the available time period of the DYN datasets.

over $10 \%$ with more vegetation in the Sahel but lower values in the eastern parts of the Sudanian zone. In the Sahel, which is especially prone to interannual PCP variations and where the bare sand is considerably brighter than vegetation, the albedo locally decreases by more than $3 \%$. The Aug-Sep spatial correlation of $\Delta \mathrm{Y}(\mathrm{VF})_{\mathrm{Dyn}}$ with the observed $\triangle \mathrm{Y}(\mathrm{PCP})$ from June is still about 0.3 and confirms the local lagged co-variation of rainfall and vegetation.

\section{Large-scale impact of interannual vegetation changes}

\subsection{Domain averages}

In the following, we investigate the plausibility of the modelled effect of year-to-year vegetation changes for Aug-Sep domain-wide averages with respect to observations. As presented in Table 2, WRF correctly captures more PCP in
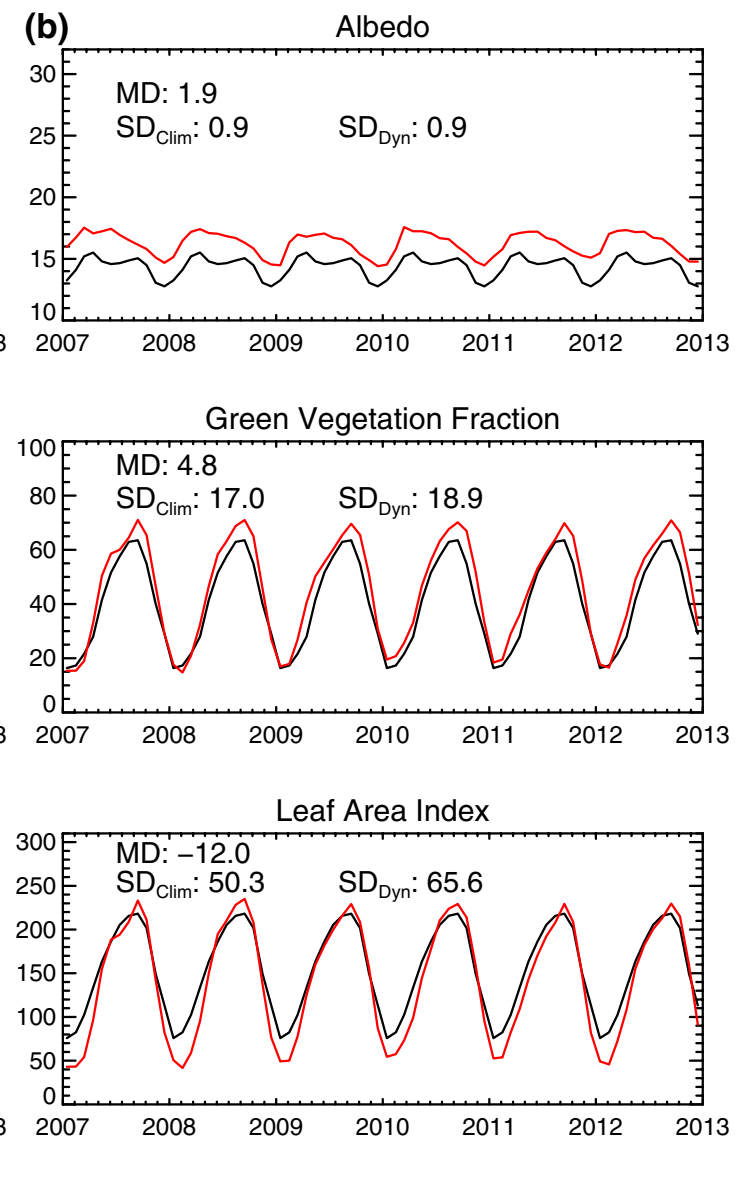

Additionally, the mean deviation between CLIM and DYN (MD) and the standard deviation (SD) for each dataset are given

2010 than in 2009 in both the DYN and CLIM case. This illustrates that the general monsoon regime is already determined by remote drivers that are fed to the WRF model via the domain boundaries from ERA-I.

DYN shows higher LH because of higher maxima in $\mathrm{VF}_{\text {Dyn }}$ (cf. Fig. 2) which reduces the bias for both surface fluxes with respect to the reference data and indicates a more realistic flux partitioning. For both years, the ratio of evapotranspiration to precipitation is $6 \%$ higher than for CLIM and also $2 \%$ higher than for the reference datasets. The sensible heat flux generally remains too high due to an overestimation of incoming solar radiation related to model uncertainties regarding the generation of clouds (not shown).

DYN also decreases the precipitation bias because of less absolute rainfall of about $12 \mathrm{~mm} \mathrm{month}{ }^{-1}$ for both years. This distinct change is most likely due to the higher values of $\mathrm{ALB}_{\text {Dyn }}(+1.8 \%$ on average) in comparison to $\mathrm{ALB}_{\text {Clim }}$ (cf. Fig. 2) leading to more reflected solar energy (countering the bias in incoming short-wave radiation), overall lower TS of about $-0.6 \mathrm{~K}$ and smaller $\mathrm{SH}$ of 


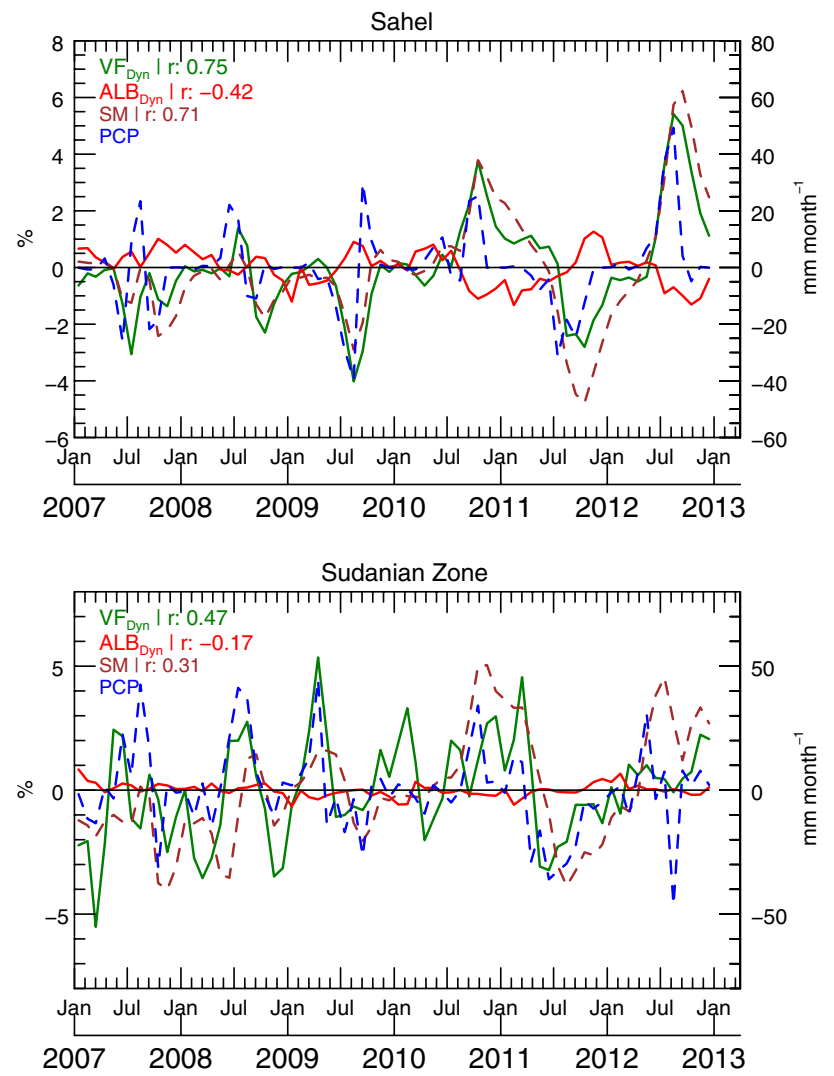

Fig. 3 Monthly anomalies of dynamical albedo $\left(\mathrm{ALB}_{\mathrm{Dyn}}\right)$, dynamical green vegetation fraction $\left(\mathrm{VF}_{\text {Dyn }}\right), \mathrm{CPC}$ soil moisture $(\mathrm{SM})$ and TRMM precipitation (PCP) with respect to the average annual cycle for 2007-2012. Correlations (r) represent +1 month time-lagged correlations with PCP

$6 \mathrm{~W} \mathrm{~m}^{-2}$. However, these improvements are related to technical differences in the albedo dataset instead of realistic surface changes and are thus purely artificial.

\section{(a)}

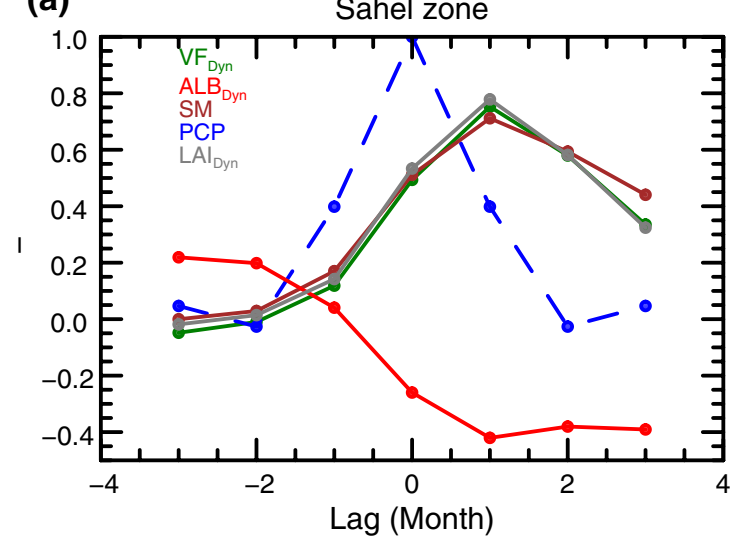

Fig. 4 Monthly time-lagged anomaly correlations with PCP for dynamical albedo $\left(\mathrm{ALB}_{\mathrm{Dyn}}\right)$, dynamical leaf area index $\left(\mathrm{LAI}_{\mathrm{Dyn}}\right)$, dynamical green vegetation fraction $\left(\mathrm{VF}_{\mathrm{Dyn}}\right)$, soil moisture $(\mathrm{SM})$
To exclude the effect of such artificial offsets, it is helpful to compare the change in $\Delta Y$, the modelled interannual difference for any variable, instead of comparing the change for a specific year.

The absolute $\Delta \mathrm{Y}$ in Table 2 is generally larger for DYN than for CLIM, as could be expected under the influence of the two opposing vegetation anomalies during 2009 and 2010.

To get an impression on the significance of the difference between $\Delta Y_{\text {Dyn }}$ and $\Delta Y_{\text {Clim }}\left(=\Delta Y_{\text {Srfc }}\right.$, cf. Eq. 1), we compare $\Delta \mathrm{Y}_{\text {Srfc }}$ to the spread of $\Delta \mathrm{Y}$ per ensemble in Fig. 6. Interestingly, the spread of $\Delta \mathrm{Y}$ for the corresponding reference datasets (blue) is always smaller than the spread of the WRF ensembles, in this case attributing larger uncertainty to the model's internal variability than to the choice of a certain reference dataset.

For PCP and SH, the WRF ensemble spreads for $\Delta \mathrm{Y}$ strongly overlap. This means that, for the study region average, instead of changing the surface information, we could have changed the initial conditions of the WRF model to produce differences of the same or an even larger margin for these two variables, rendering $\Delta \mathrm{Y}_{\text {Srfc }}$ insignificant. The spread in PCP increases by $83 \%$ from $12 \mathrm{~mm} \mathrm{month}^{-1}$ for $\Delta \mathrm{Y}_{\mathrm{Clim}}$ to $22.3 \mathrm{~mm} \mathrm{month}^{-1}$ for $\Delta \mathrm{Y}_{\text {Dyn }}$, suggesting that the dynamical surface considerably increases the internal variability of precipitation generation in the model.

Other than for PCP, the $\Delta \mathrm{Y}_{\mathrm{Srfc}}$ cooling signal of $-0.1 \mathrm{~K}$ for TS and the related $\mathrm{LH}\left(+3.3 \mathrm{~W} \mathrm{~m}^{-2}\right)$ is significant $(P \leq 0.01)$, estimated by a two-tailed $t$ test. In accordance to the observations, DYN shows a positive $\Delta \mathrm{Y}(\mathrm{LH})$, although overestimates. CLIM does not produce a clear difference in LH between the two years suggesting that the dynamical vegetation improves the models ability to represent the interannual difference of LH in this case. Associated with

(b)

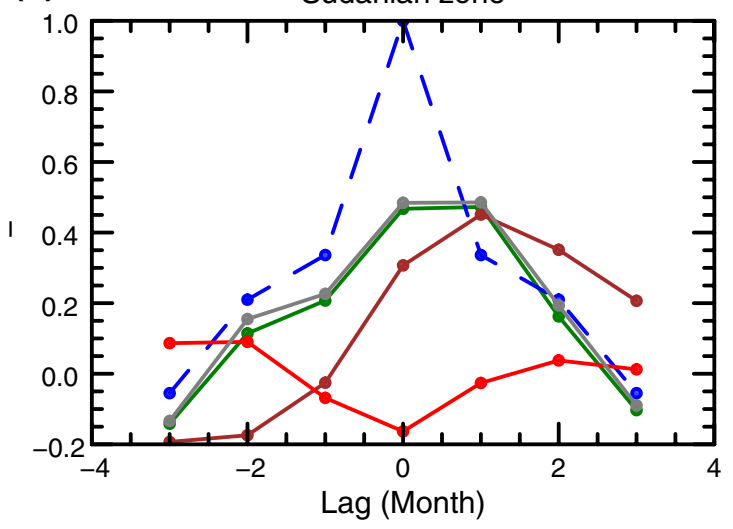

and precipitation (PCP) in a the Sahel and $\mathbf{b}$ the Sudanian zone. The anomalies are derived with respect to the 2007-2012 average annual cycle 

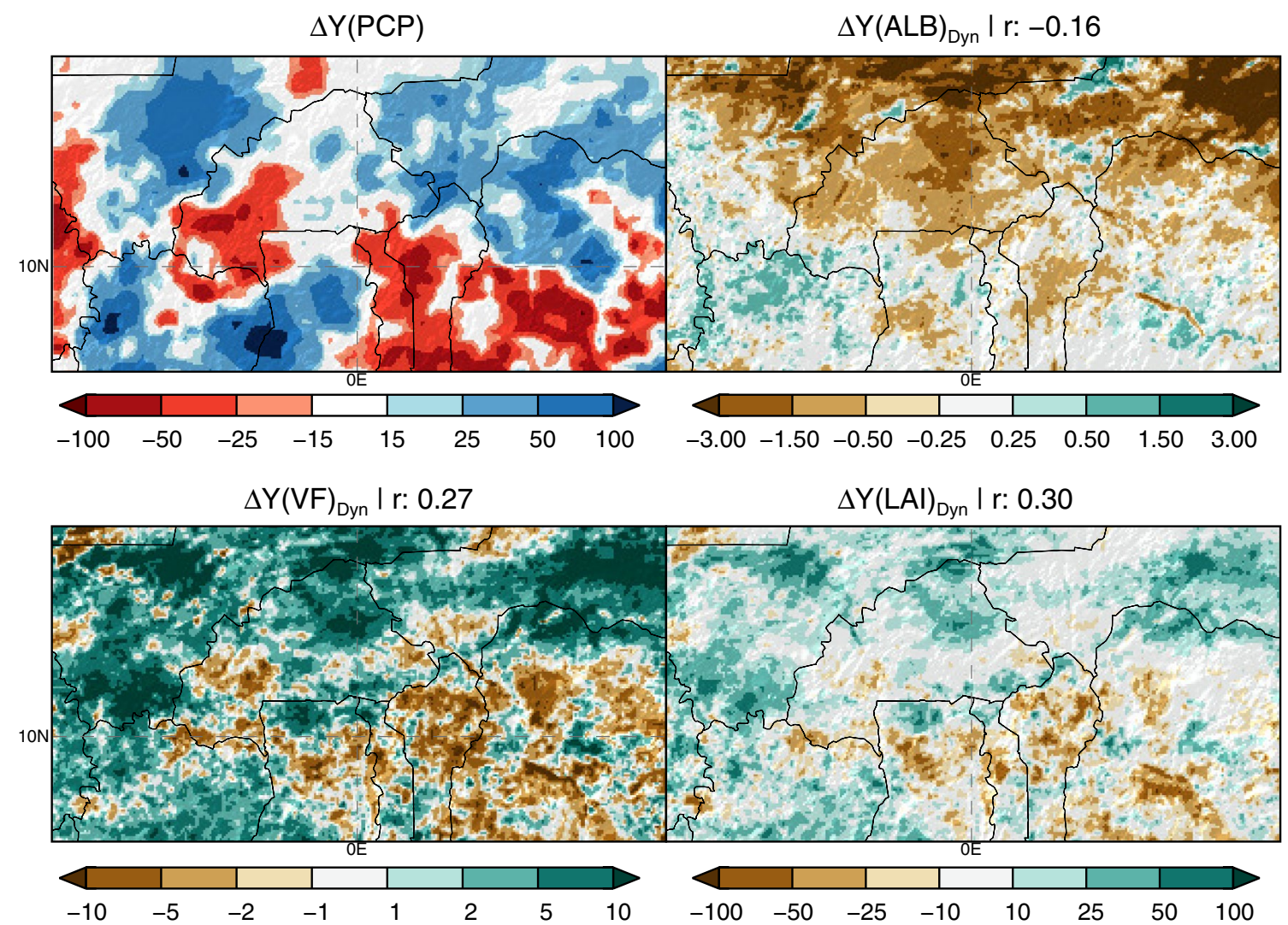

Fig. 5 Average interannual differences 2010-2009 ( $\Delta$ Y) for JuneJuly precipitation (PCP, average of TRMM, RFE and CMORPH, $\mathrm{mm}$ month $^{-1}$ ) and August-September dynamical albedo (ALB ${ }_{\text {Dyn }}$,

$\mathrm{LH}$, the decrease in TS is too strong for DYN, indicating a too large sensitivity of surface fluxes on changing vegetation conditions in the WRF model that leads to a larger $\Delta \mathrm{Y}$ than observed. This overestimated sensitivity of $\Delta \mathrm{Y}(\mathrm{LH})_{\text {Dyn }}$ to vegetation change might partly be related to an overestimation of the LAI due to the simple upscaling via averaging.

\subsection{Meridional distributions}

The clear impact of vegetation changes on TS raises the question whether the monsoon dynamics, such as the African Easterly Jet (AEJ), could also be affected. Being a thermal wind, the AEJ follows the largest temperature gradient over the continent that can be modulated by vegetation patterns. Disturbances of the AEJ may trigger or support mesoscale convective systems (MCS) in its proximity and a shift of the jet may therefore change the meridional distribution of precipitation (Cook 1999).

The normalized meridional cross-sections in Fig. 7a reveal a broadened but weaker maximum of the Sahelian temperature gradient between 1 and $15^{\circ} \mathrm{N}$ in 2010 compared to CLIM. The resulting northward shift of the AEJ leads to a better representation of the difference between
$\%)$, vegetation fraction $\left(\mathrm{VF}_{\text {Dyn }}, \%\right)$ and leaf area index $\left(\mathrm{LAI}_{\text {Dyn }}, \%\right)$. Spatial correlations (r) are with respect to $\triangle \mathrm{Y}(\mathrm{PCP})$

the 2010/2009 AEJ positions with respect to ERA-I. Accordingly, the precipitation peak in the Sahel for $\Delta \mathrm{Y}_{\mathrm{Dyn}}$ is broadened to the north (Fig. 7b) and directly coincides with the largest $\Delta \mathrm{Y}_{\mathrm{Dyn}}$ for VF and LH (cf. Fig. 7c). This PCP increase is however not visible in the reference datasets. Instead, WRF generally overestimates $\triangle \mathrm{Y}(\mathrm{PCP})$ in the Sahel and DYN further increases this positive bias via a positive feedback between $\mathrm{LH}$ and PCP.

The vegetation-induced change in $\Delta \mathrm{Y}(\mathrm{LH})$ is directly proportional to $\Delta \mathrm{Y}(\mathrm{VF})$, as the overlapping curves for $\Delta \mathrm{Y}_{\text {Srfe }}$ in Fig. 7c illustrate. However, such a straightforward relationship does not exist for $\Delta \mathrm{Y}(\mathrm{PCP})_{\text {Srfc }}$ : Although $\Delta \mathrm{Y}(\mathrm{VF})_{\mathrm{Srfc}}$ is generally positive, there is a negative effect on PCP between 10 and $12^{\circ} \mathrm{N}$ (Fig. $7 \mathrm{~b}, \Delta \mathrm{Y}_{\text {Srfc }}$ ) that we only find in CMORPH amongst the observations. A further examination of $\Delta \mathrm{Y}_{\mathrm{Srfc}}$ in Fig. 7a reveals that in this region, the temperature (and pressure) gradient is weakened by the stronger vegetation gradient, suggesting a relatively lower near-surface moisture convergence that leads to reduced rainfall. Correspondingly, the areas with a positive feedback on PCP are marked by a stronger temperature (pressure) gradient (positive $\Delta \mathrm{Y}_{\text {Srfc }}$ ). 
Fig. 6 Aug-Sep $\Delta Y$ boxplots for precipitation (PCP), surface temperature (TS), sensible $(\mathrm{SH})$ and latent $(\mathrm{LH})$ heat flux that span the spread (S) in $\Delta \mathrm{Y}$ of the WRF ensembles (DYN, CLIM) and for the reference datasets over the study area. The whiskers indicate minimum and maximum $\Delta \mathrm{Y}$. For the WRF ensembles, the spread of $\Delta \mathrm{Y}$ is computed via the cartesian product of the four 2009/2010 pairs. Therefore, each box consists of $16 \Delta \mathrm{Y}$. For the observations, the box spread consists of three $\Delta Y$ values of three single reference datasets. $\Delta \mathrm{Y}_{\mathrm{Srfc}}$ is the difference of the mean values (red lines $\left.\Delta Y_{D y n}-\Delta Y_{C l i m}\right)$
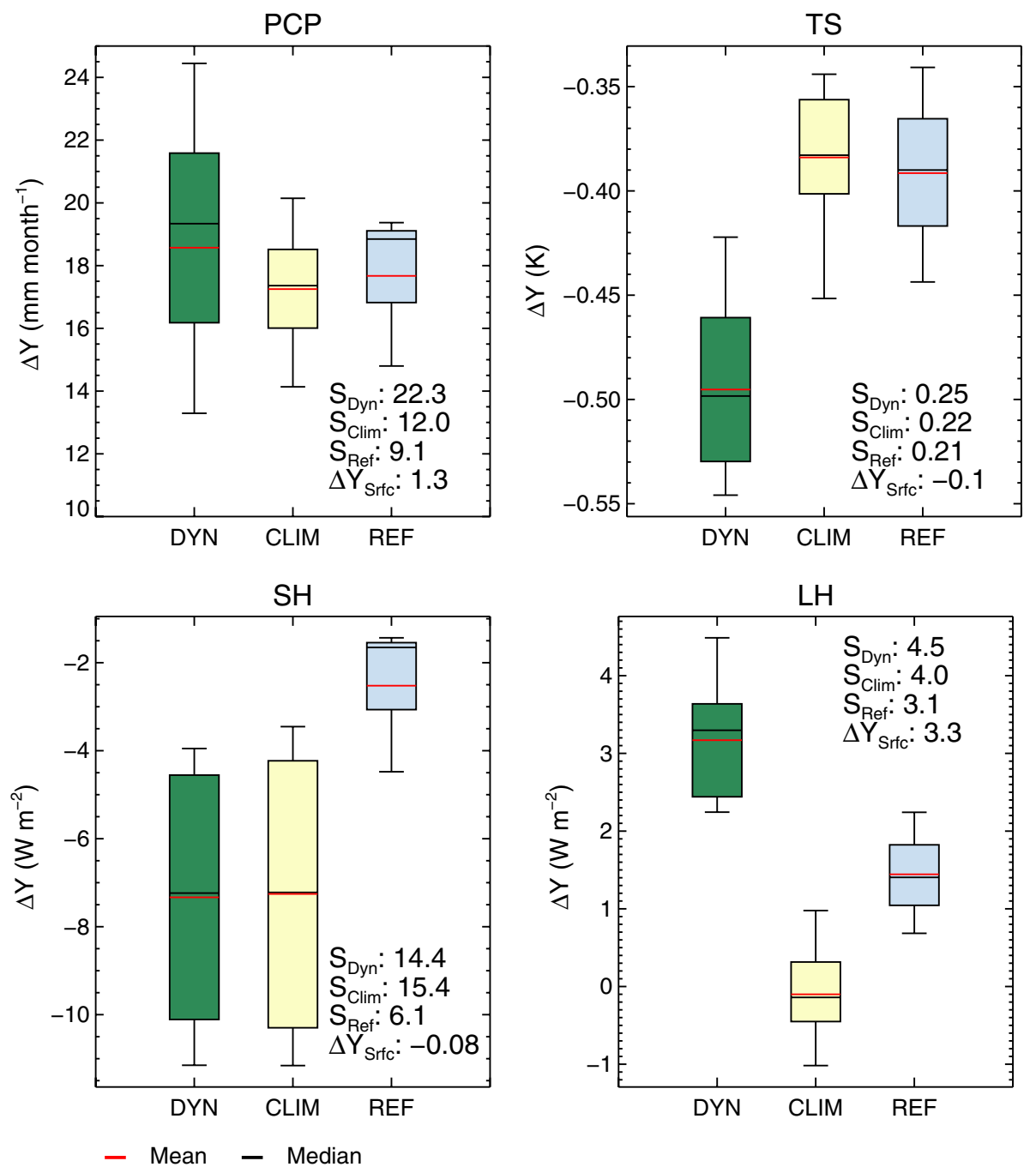

This confirms that large-scale differential heating due to vegetation heterogeneities can affect the dynamics and related precipitation even on continental scale. However, in this case, DYN reduces the correspondence of modelled LH and PCP change with the average of the observational datasets, shown by higher mean absolute deviations (MAD) and lower $\mathrm{r}^{2}$. Again, the change in LH with vegetation and the resulting lower surface temperatures seem to be overestimated, especially in the Sahel, leading to an exaggerated effect on the meridional gradients.

In summary, CLIM is able to capture the domain wide interannual differences of variable averages and meridional gradients as good or better than DYN. While the dynamical vegetation even exerts a clear influence on the modelled monsoon dynamics, the magnitude seems to be overestimated. We therefore conclude that large-scale drivers dominate the observed interannual changes and that a dynamical land surface description does not add clear value at this seasonally averaged spatio-temporal scale within the uncertainty range of observations. It remains to be answered whether the changing vegetation patterns might exhibit a regional or local effect that cannot be captured by CLIM.

\section{Regional and local effects of vegetation patterns}

In the previous section we showed that, even on a larger scale, vegetation significantly influences changes of LH and TS. Changes in both should be even more pronounced on regional and local scales and might, under favourable atmospheric conditions, affect PCP.

To get an impression of regional vegetation-induced changes of TS, LH and the evaporative fraction (EF), Fig. 8 shows their $\Delta \mathrm{Y}_{\text {Srfc }}$ and their spatial correlation with

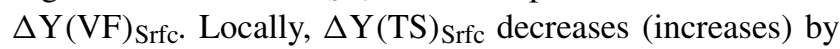
over $1 \mathrm{~K}$ with increasing (decreasing) $\Delta \mathrm{Y}(\mathrm{VF})_{\text {Srfc. The }}$ changes in $\Delta \mathrm{Y}(\mathrm{LH})_{\text {Srfc }}$ mostly range between -10 and $+20 \mathrm{~W} \mathrm{~m}^{-2}$. A distinct increase of $\Delta \mathrm{Y}(\mathrm{EF})_{\mathrm{Srfc}}$ of more than $9 \%$ is only visible in the Sahel and at the southern border of the domain. The difference patterns match those 

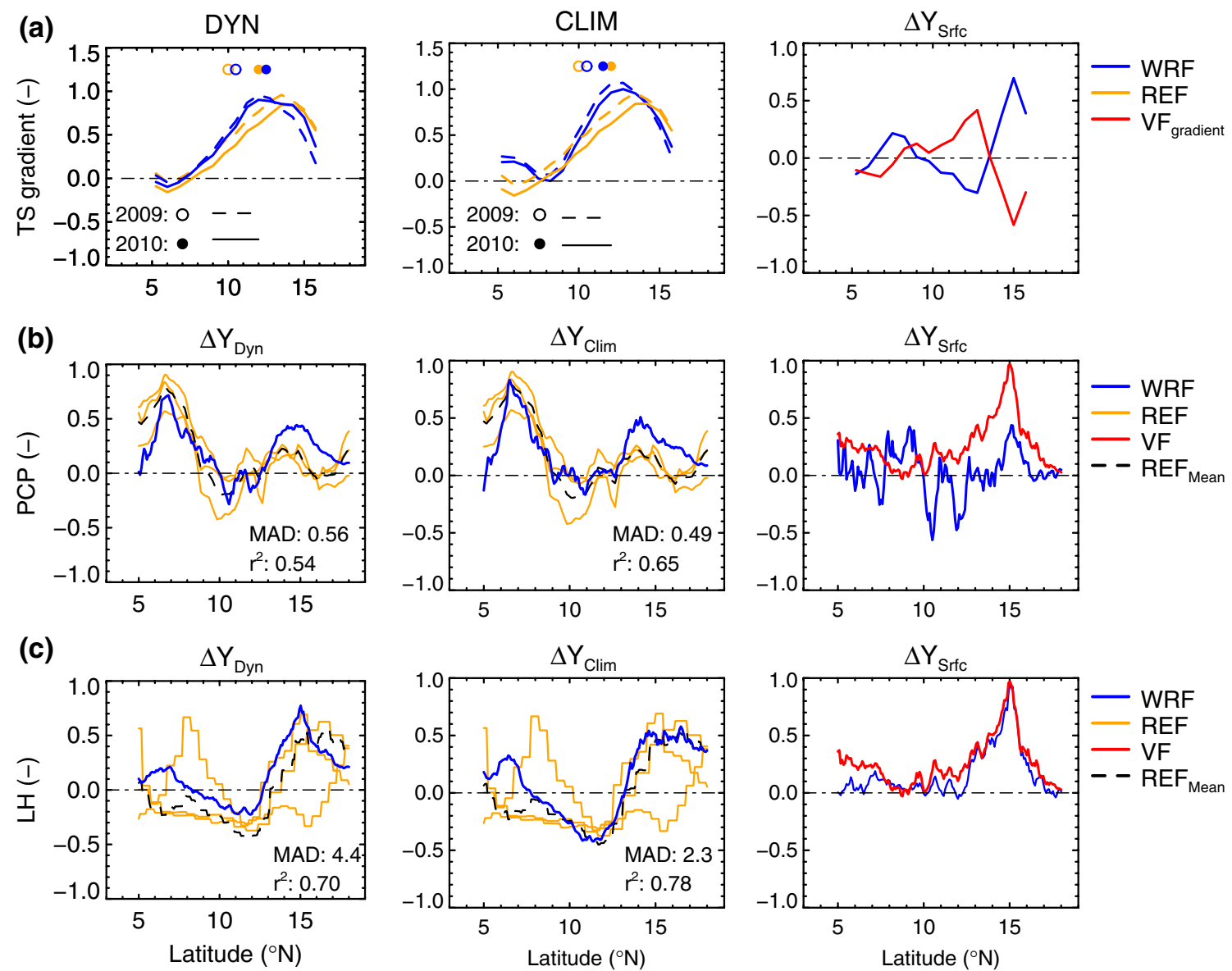

Fig. 7 a The Aug-Sep meridional gradient of surface temperature (TS) for DYN/ CLIM (WRF) in 2009 and 2010 compared to GHCN (REF) and the resulting $\Delta \mathrm{Y}_{\text {Srfc }} \Delta \mathrm{Y}_{\text {Srfc }}$ represents the change in each variable between the two years that is solely induced by the interannual change in vegetation patterns. The TS gradient $(\mathrm{dT} / \mathrm{dx})$ is computed with a moving window at spatial intervals of $75 \mathrm{~km}$ as the difference between poleward and equatorward temperature (dT) over a change in distance of $150 \mathrm{~km}(\mathrm{dx})$. Additionally, the position of the AEJ (circles) is shown for each year. The latitudinal position of the AEJ is defined as the first occurrence of the zonal wind velocity sur-

of $\Delta \mathrm{Y}(\mathrm{VF})_{\mathrm{Srfc}}$ with correlations of -0.74 for $\Delta \mathrm{Y}(\mathrm{TS})_{\mathrm{Srfc}}$, 0.72 for $\Delta \mathrm{Y}(\mathrm{LH})_{\mathrm{Srfc}}$ and 0.7 for $\Delta \mathrm{Y}(\mathrm{VF})_{\mathrm{EF}}$.

However, the slopes of the zonal linear fit between the variables and $\Delta \mathrm{Y}(\mathrm{VF})_{\mathrm{Srfc}}$ in the right panels in Fig. 8 reveal latitudinal differences in the strength of the response per unit of VF change. Especially around $10^{\circ} \mathrm{N}$, where the monsoon precipitation peaks for both years (cf. meridional precipitation distribution, Fig. 8a), the effect of vegetation on the moist surface variables is smaller than at the northern or southern borders of the study domain.

\subsection{Surface response and the evaporative regime}

The meridional differences in the surface response to vegetation changes are an expected result if we consider two passing $10 \mathrm{~m} \mathrm{~s}^{-1}$ between 650 and $550 \mathrm{hPa}$. b, c Aug-Sep meridional cross-sections of $\Delta \mathrm{Y}$ and $\Delta \mathrm{Y}_{\mathrm{Srfc}}$ for the zonal average of precipitation (PCP) and latent heat flux (LH) for DYN/ CLIM (WRF) compared to the PCP reference datasets (REF: TRMM, RFE, CMORPH) and the LH reference datasets (REF: MTE, ERA Interim/LAND, MERRA-Land). Additionally, $\Delta \mathrm{Y}_{\text {Srfc }}$ for the vegetation fraction (VF) or the $\mathrm{VF}$ gradient $\left(\mathrm{VF}_{\text {gradient }}\right.$ ) are given for comparison. All variables are normalized with respect to their value range $(\max -\min )$ and are therefore dimensionless. The mean absolute deviation (MAD, PCP: $\mathrm{mm}$ day $^{-1}$, LH: $\mathrm{W} \mathrm{m}^{-2}$ ) and $\mathrm{r}^{2}$ are with respect to $\mathrm{REF}_{\text {Mean }}$

factors that modify the impact of vegetation on spatial $\mathrm{LH}$ variability: (1) the evaporative regime and thus the variable that limits evapotranspiration, (2) the actual difference between transpiration and bare soil evaporation.

Regarding the first factor (1), Seneviratne et al. (2010) distinguish between moisture-limited regimes, where soil moisture (SM) changes have a maximum effect on the turbulent surface fluxes, and energy-limited regimes where SM is plenty and these fluxes are limited by incoming solar radiation. Only in the moisture-limited regime, vegetation (root zone soil moisture) can act as a first-order constraint for LH changes, analogous to moist bare soil.

In the moist region of the monsoon rainband however, the frequent cloud cover limits the available energy for 
(a) ${ }_{\Delta \mathrm{Y}(\mathrm{VF})_{\mathrm{SHC}}}$
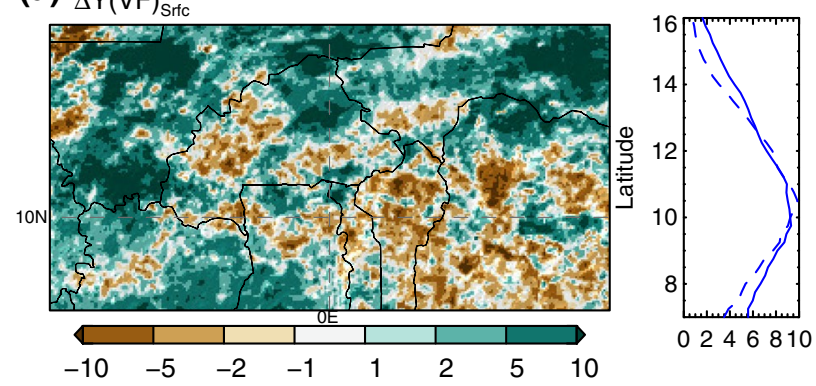

(b) $\Delta \mathrm{Y}(\mathrm{TS})_{\mathrm{SHC}} \mid \mathrm{r}:-0.74$
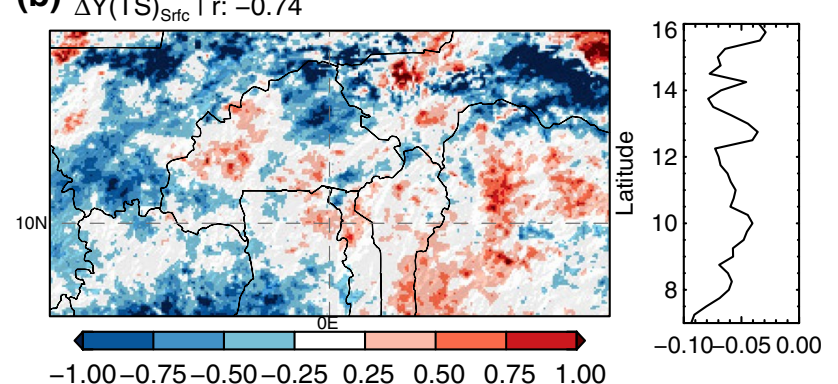

(c) $\Delta \mathrm{Y}(\mathrm{LH})_{\mathrm{Srcc}} \mathrm{I}$ r: 0.72
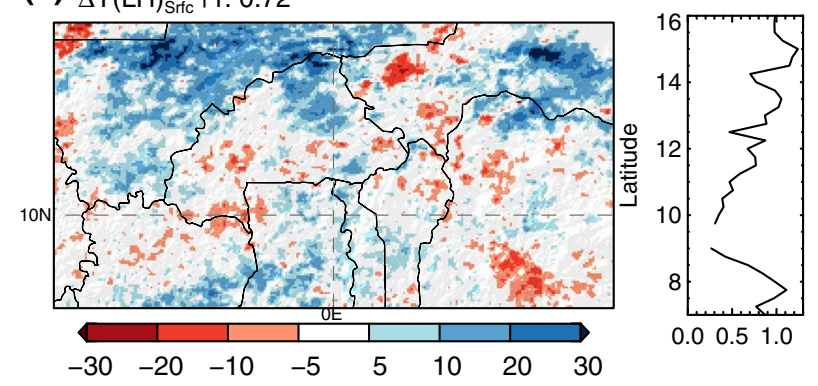

(d) $\Delta \mathrm{Y}(\mathrm{EF})_{\mathrm{SrC}} \mid \mathrm{r}: 0.70$
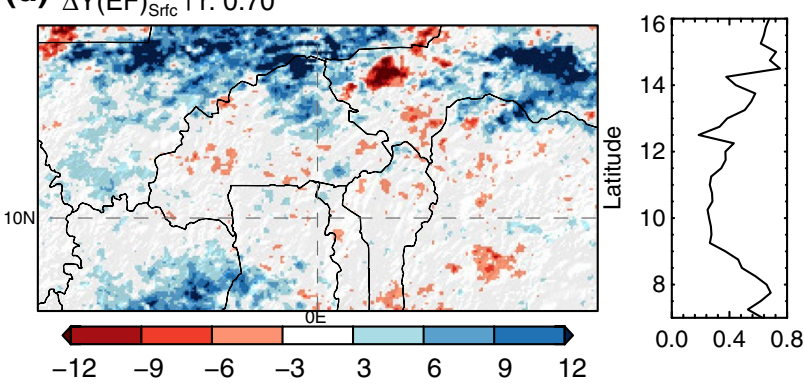

Fig. 8 Left Aug-Sep maps of $\Delta \mathrm{Y}_{\text {Srfc }}$ for a vegetation fraction (VF, $\%)$, b surface temperature (TS, $\mathrm{K})$, c latent heat flux $\left(\mathrm{LH}, \mathrm{W} \mathrm{m}^{-2}\right.$ ) and $\mathbf{d}$ evaporative fraction (EF, \%). $\mathrm{EF}$ is defined as the ratio of latent heat flux to the sum of latent and sensible heat fluxes. Spatial correlations (r) are with respect to $\Delta \mathrm{Y}(\mathrm{VF})_{\text {Srfe. }}$ Only significant $\Delta \mathrm{Y}_{\mathrm{Srfc}}$ are shown $(P \leq 0.01)$ and taken into account to compute r. Right $\mathbf{a}$ the meridional average precipitation $\left(\mathrm{mm} \mathrm{day}^{-1}\right.$, 2010: solid, 2009: dashed) and $\mathbf{b}-\mathbf{d}$ the coefficients $a$ (the slope) of the zonal slices linear fit $(a x+b)$ between $\Delta \mathrm{Y}(\mathrm{VF})_{\mathrm{Srfc}}$ and $\Delta \mathrm{Y}(\mathrm{TS})_{\mathrm{Srfc}}, \Delta \mathrm{Y}(\mathrm{LH})_{\mathrm{Srfc}}$ and $\Delta \mathrm{Y}(\mathrm{EF})_{\text {Srfc }}$, respectively. Missing values indicate no correlation for the zonal slice

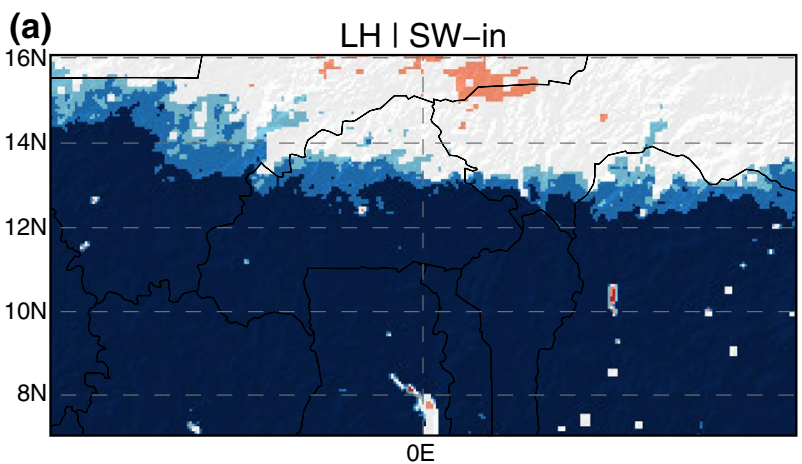

(b)

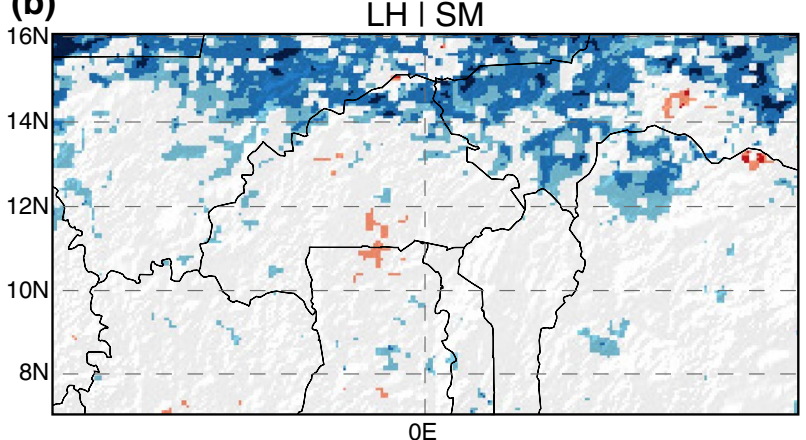

(c)

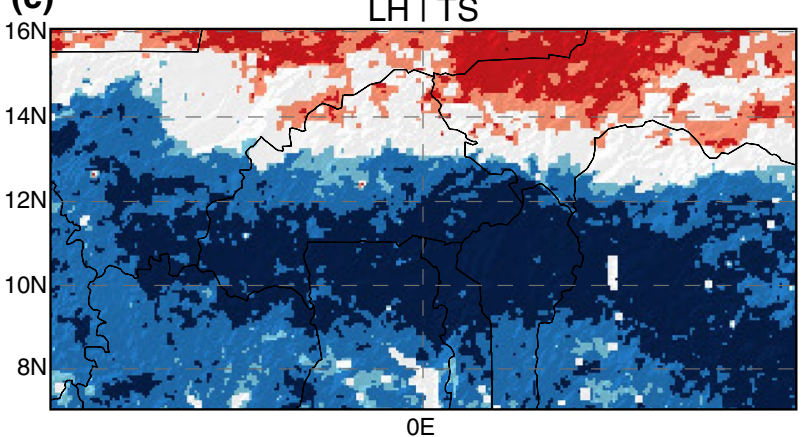

(d)

$\mathrm{LH}$ I SH

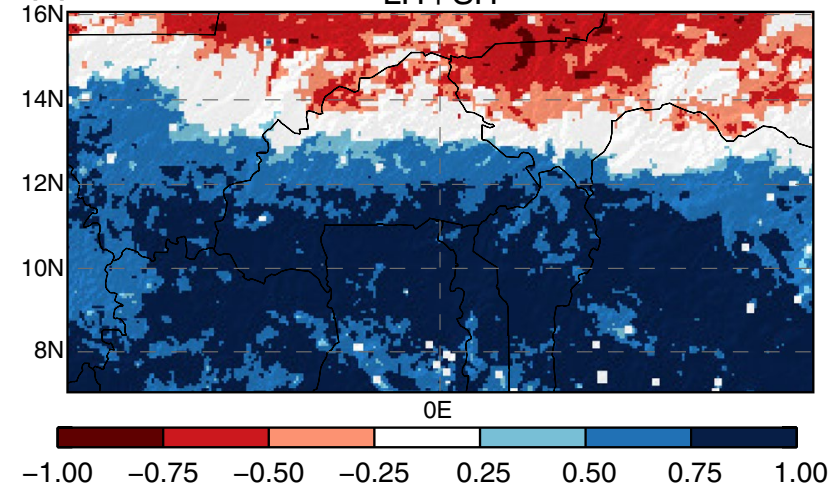

Fig. 9 Maps of Aug-Sep temporal correlations of daily $\Delta \mathrm{Y}_{\text {Srfc }}$ between the latent heat flux (LH) and a incoming short-wave radiation (SW-in), b soil moisture (SM), c surface temperature (TS) and d sensible heat flux $(\mathrm{SH})$. Only significant correlations $(P \leq 0.01)$ are shown 
evapotranspiration and LH patterns are therefore predominantly controlled (limited) by incoming short-wave radiation, reducing the secondary effect of spatial variations in vegetation. For the investigated time period, the transition zone of the two regimes lies approximately between 12 and $14^{\circ} \mathrm{N}$, as depicted in Fig. 9a. In the Sahel, positive daily correlations between $\Delta \mathrm{Y}(\mathrm{LH})_{\mathrm{Srfc}}$ and $\Delta \mathrm{Y}(\mathrm{SM})_{\mathrm{Srfc}}$ illustrate the moisture-limited region, while throughout the Sudanian zone, $\Delta \mathrm{Y}(\mathrm{LH})_{\mathrm{Srfc}}$ variability is controlled by incoming short-wave radiation.

The second factor (2) that affects the ratio of $\Delta \mathrm{Y}(\mathrm{LH})_{\mathrm{Srfc}}$ and $\Delta \mathrm{Y}(\mathrm{VF})_{\mathrm{Srfc}}$ is related to the fact that vegetation exhibits an evaporative advantage compared to bare soil. The advantage exists because the volume of water in the soil that is available for vegetation transpiration is larger than for soil evaporation. This is especially important in the Sahel, where the surface soil layer dries out quickly and where vegetation provides a profound longer-lasting moisture supply to the atmosphere, resulting in stronger $\mathrm{LH}$ changes in response to VF changes. This effect is less important in the Sudanian zone, where surface soil moisture is replenished more frequently.

Nevertheless, we also identify an increased sensitivity to $\Delta \mathrm{Y}(\mathrm{VF})_{\mathrm{Srfc}}$ at the southern border of the domain in Fig. 8, where we find an increase of $\Delta \mathrm{Y}(\mathrm{LH})_{\mathrm{Srfc}}$ of $1 \mathrm{~W} \mathrm{~m}^{-2}\left(0.04 \mathrm{~mm} \mathrm{day}^{-1}\right)$ per unit $\Delta \mathrm{Y}(\mathrm{VF})_{\text {Srfc }}$, comparable to the moisture-limited Sahel. This is because the evaporative advantage also increases when vegetation density increases due to a larger evaporative surface as compared to the bare ground. The canopy is much more dense in the Sudanian zone as illustrated in Fig. 2 with a more than two times higher LAI than in the Sahel. Consequently, a high amount of available root zone soil moisture in dry regimes as well as a high canopy density in wet regimes contribute to a stronger increase of $\Delta \mathrm{Y}(\mathrm{LH})_{\text {Srfc }}$ per increase of unit $\Delta \mathrm{Y}(\mathrm{VF})_{\text {Srfc. }}$.

Interestingly, $\Delta \mathrm{Y}(\mathrm{TS})_{\text {Srfc }}$ does not reproduce the behaviour of $\Delta \mathrm{Y}(\mathrm{LH})_{\mathrm{Srfc}}$ in the Sahel (Fig. 8b). While the decrease in $\Delta \mathrm{Y}(\mathrm{TS})_{\text {Srfc }}$ per unit $\Delta \mathrm{Y}(\mathrm{VF})_{\mathrm{Srfc}}$ is indeed somewhat stronger $(-0.09 \mathrm{~K})$ in the southern Sudanian zone, the relationship varies around $-0.05 \mathrm{~K}$ in the rest of the domain. One reason for this is that on smaller timesteps, a net-warming in the vegetated areas may occur when soil moisture is not sufficient to supply transpiration. In these cases, we find a daytime heating effect irrespective of a positive or negative $\Delta \mathrm{Y}(\mathrm{VF})_{\mathrm{Srfc}}$, consequently weakening the time-averaged overall cooling by a positive $\Delta \mathrm{Y}(\mathrm{VF})_{\text {Srfc. }}$
In agreement with $\Delta \mathrm{Y}(\mathrm{LH})_{\mathrm{Srfc}}$, the temporal variability of $\Delta \mathrm{Y}(\mathrm{TS})_{\mathrm{Srfc}}$ is affected by the predominant evaporative regime. Figure $9 \mathrm{~b}$ reveals that only north of the transition zone at about $12^{\circ} \mathrm{N}$, changes in the $\Delta \mathrm{Y}_{\text {Srfe }}$ of temperature and turbulent heat flux partitioning are predominantly controlled by changes in $\Delta \mathrm{Y}(\mathrm{LH})_{\text {Srfc }}$ (negatively correlated), depending on the availability of soil moisture.

Opposed to that, the positive correlation between $\Delta \mathrm{Y}(\mathrm{LH})_{\mathrm{Srfc}}$ and $\Delta \mathrm{Y}(\mathrm{TS})_{\text {Srfc }}$ in the energy-limited Sudanian zone is a spurious correlation that is actually linked to the dependence of both variables on solar radiation which also applies to the relationship of $\Delta \mathrm{Y}(\mathrm{LH})_{\mathrm{Srfc}}$ and $\Delta \mathrm{Y}(\mathrm{SH})_{\text {Srfc }}$ (Fig. 9d). The $\Delta \mathrm{Y}_{\mathrm{Srfc}}$ of surface temperatures and both turbulent fluxes increase simultaneously (positive correlation) with a higher $\Delta \mathrm{Y}_{\mathrm{Srfc}}$ of the incoming solar radiation, explaining the weaker response of $\Delta Y(E F)_{\text {Srfc }}$ to $\Delta \mathrm{Y}(\mathrm{VF})_{\text {Srfc }}$ changes in Fig. $8 \mathrm{~d}$.

These two different process pathways of dominant temperature control via soil-moisture anomalies (terrestial control) or via radiation anomalies (atmospheric control) were also identified by Berg et al. (2015) in a comparison of a set of climate simulations with and without interactive soil moisture. They conclude that land-atmosphere feedbacks in energy-limited regions can only play a minor role, since solar radiation determines temporal surface temperature variability. This drives latent heat flux variability which then drives soil moisture variability. This finding is supported by Dirmeyer (2011), who points out that the identification of strong surface-atmosphere coupling (e.g. a high correlation of the surface state and the atmospheric response) is only valid if there is surface (e.g. soil moisture) variability in time.

However, this purely temporal definition of land-atmosphere coupling does not take into account that persistent spatial surface characteristics might also have a considerable effect on the atmosphere. In the case of vegetation, we see from Fig. 8 that, although solar radiation controls the temporal changes of the surface variables in the Sudanian zone, the long-lasting vegetation patterns lead to aggregated spatial characteristics of TS and LH. We assume that such persistent surface gradients may force the atmosphere to reoccurring states just like, for example, a cold lake surface may impose frequent subsidence on the overlying air masses such that precipitation is suppressed. To be able to trace a land-atmosphere feedback for a temporally slowly changing feature like vegetation, we therefore define the vegetation-atmosphere feedback as the spatial correlation of atmospheric characteristics with vegetation patterns over an aggregated time period as opposed to the temporal correlation approach. 


\subsection{The modelled atmospheric footprint}

We now want to investigate whether the vegetationdriven change in patterns of the surface variables have a local effect on interannual changes in the atmosphere. As explained before, the vegetation patterns are relatively static with respect to typical atmospheric time scales. A land-atmosphere feedback (if any) should therefore manifest itself in a spatial accumulation of certain atmospheric states if the interannual vegetation change is strong enough to force the atmosphere.

The significant spatial correlations between $\Delta \mathrm{Y}(\mathrm{VF})_{\mathrm{Srfc}}$ and the $\Delta \mathrm{Y}_{\text {Srfc }}$ of the different atmospheric variables (ranging from 0.46 to $-0.76, P \leq 0.01$ ) in Fig. $10 \mathrm{a}-\mathrm{d}$ indeed show that the surface characteristics modify the conditions in the PBL. The correlation coefficients are generally lower than for the surface variables, not only because the atmospheric sensitivity is ultimately determined by large-scale conditions, but also because our method can only capture pixelwise coinciding interactions between VF and the atmosphere. Therefore, we cannot relate any downstream changes in the atmosphere to their origin at the surface, for example.

Another factor for lower spatial correlations is the smallscale spatial heterogeneity of VF as compared to the wellmixed PBL conditions. To remedy this scale discrepancy, $\mathrm{VF}$ was upscaled to a length scale of $15 \mathrm{~km}$, which is supposedly at the lower end at which PBL anomalies might persist and impact convection (Clark and Taylor 2004).

In accordance to $\Delta \mathrm{Y}(\mathrm{TS})_{\mathrm{Srfc}}$, the $\Delta \mathrm{Y}_{\mathrm{Srfc}}$ of the height of the PBL is anti-correlated with the interannual change in $\mathrm{VF}$, which is most pronounced in regions where $\Delta \mathrm{Y}(\mathrm{VF})_{\mathrm{Srfc}}$ surpasses $10 \%$ (cf. Fig. 8a). In regions with a positive vegetation change $\Delta \mathrm{Y}(\mathrm{VF})_{\text {Srfc }}$ and corresponding negative $\Delta \mathrm{Y}_{\text {Srfc }}$ for PBL heights, we find an increase of daytime hours in which the lifted condensation level (LCL) lies within the PBL (Fig. 10b). This is because more moisture (higher LH) trapped in a lower PBL increases the relative humidity which ultimately lowers the LCL and leads to cloud formation. Note that this cloud formation process via PBL moistening is less frequent in the Sahel (local increases of 20-40 h), where the air is usually far from saturated due to less moisture advection (see also Findell and Eltahir 2003 for a description of the surface-driven mechanisms of cloud formation via moistening or warming of the PBL).

Although there is a tendency to more frequent cloud cover over regions with positive $\Delta \mathrm{Y}(\mathrm{VF})_{\text {Srfc }}$ during the day, this does not necessarily imply an increase in precipitation. For example, in the South of Mali, $\Delta \mathrm{Y}(\mathrm{VF})_{\mathrm{Srfc}}$ is strongly positive and locally causes over $+60 \mathrm{~h}$ in which the LCL lies within the PBL. However, there is no significant increase in the $\Delta \mathrm{Y}_{\text {Srfc }}$ of the convective available potential energy (CAPE) (Fig. 10a) suggesting that there is no additional destabilization of the atmosphere.
On the contrary, the number of daytime rainy hours is decreased over this region (Fig. 10e), indicating that higher VF fosters the formation of shallow clouds but decreases the potential for initiation of deep convection in the afternoon. Hohenegger et al. (2009) suggest that the development of shallow clouds is an important ingredient for the negative vegetation-precipitation feedback due to higher stability of the air above the PBL related to the longwave radiative cooling at the cloud tops. Garcia-Carreras et al. (2011) analysed convective cloud distributions over crop land and forests with large eddy simulations and attribute the suppressed initiation of convection over forests to a stabilizing capping layer of warm air due to subsidence above the mixed layer. They found this subsidence to be part of mesoscale flows initiated by temperature gradients between the two vegetation classes.

Such mesoscale horizontal flows are also visible in our simulations between cooler and warmer surface patches in Fig. 10c, d, where cooler near surface temperatures and shallower mixing layers correspond to a $\Delta \mathrm{Y}_{\text {Srfc }}$ signal of diverging winds that induce a negative VF-PCP feedback. The converging wind vectors over warmer regions indicate increased moisture convergence from the surroundings that favours the initiation of convection and ultimately increases the number of rainy hours during the day (Fig. 10e).

During the night however, there is a distinct increase of rainy hours over the positive $\Delta \mathrm{Y}(\mathrm{VF})_{\text {Srfe }}$ in southern Mali (Fig. 10f). This signal is weaker in the rest of the domain but the correlation coefficients in Fig. 10e, f indeed indicate an overall negative (positive) VF-PCP feedback during the day (night). Overall, for $62 \%$ of the pixels $(n=3990)$ that show a shift of the diurnal maximum PCP from night (day) to day (night) between 2009 and 2010, this shift coincides with negative (positive) $\Delta \mathrm{Y}(\mathrm{VF})_{\text {Srfc }}$, which is $12 \%$ more likely than what we would expect by chance (Fig. 10g). The absolute $\Delta \mathrm{Y}_{\text {Srfc }}$ of rainy hours (positive and negative) in the Sahel is $10 \%$ higher during the night than during the day, indicating a slightly stronger effect of the positive VF-PCP feedback on nocturnal rainfall. In the Sudanian zone, the absolute $\Delta \mathrm{Y}_{\text {Srfc }}$ of rainy hours are similar for night and day.

Our findings are in line with Taylor et al. (2010), who analysed a MCS that was observed during the AMMA special observing period (Redelsperger et al. 2006) and report deepest convection over wet surface patches during its mature stage during the night (2130 UTC) while all areas of new convection emerged over drier soils. While the afternoon initiation of new convective cells is favoured over drier soil patches where thermals are more intense, nighttime PCP mostly falls from already existing convective systems that are enhanced by moist surfaces (Gantner and Kalthoff 2010). Wet soils have a stronger effect on the lifetime and strength of the MCS in the Sahel where moisture is limited, which might explain the enhanced positive feedback of vegetation in that region. 
(a) $\Delta \mathrm{Y}(\mathrm{CAPE})_{\mathrm{Srrc}} \mathrm{I}$ : 0.46

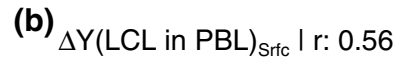

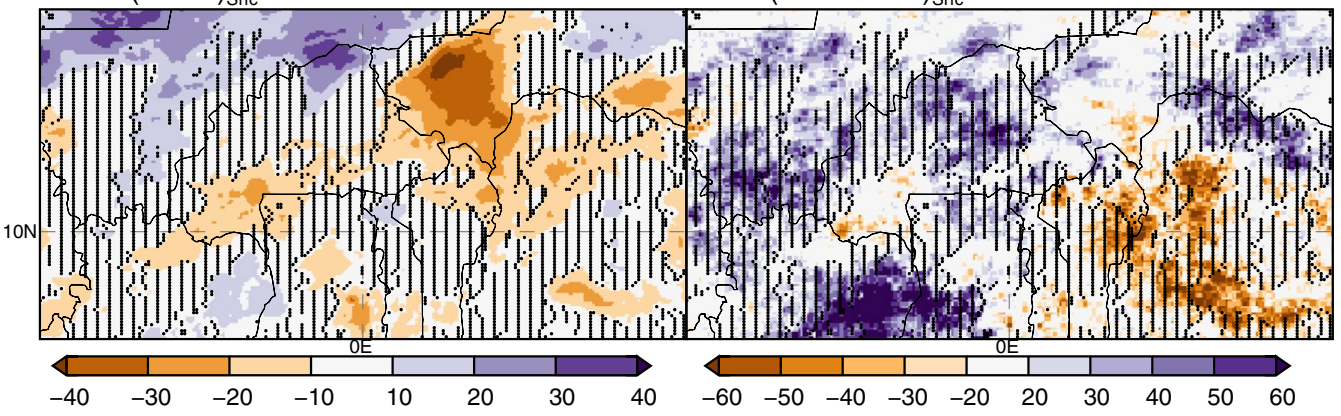

(c) $\Delta \mathrm{Y}(\mathrm{T} 2)_{\mathrm{Srfc}} \mid \mathrm{r}:-0.76$

(d) $\Delta \mathrm{Y}(\mathrm{PBL} \text { height })_{\mathrm{Srfc}} \mathrm{I}$ : -0.64

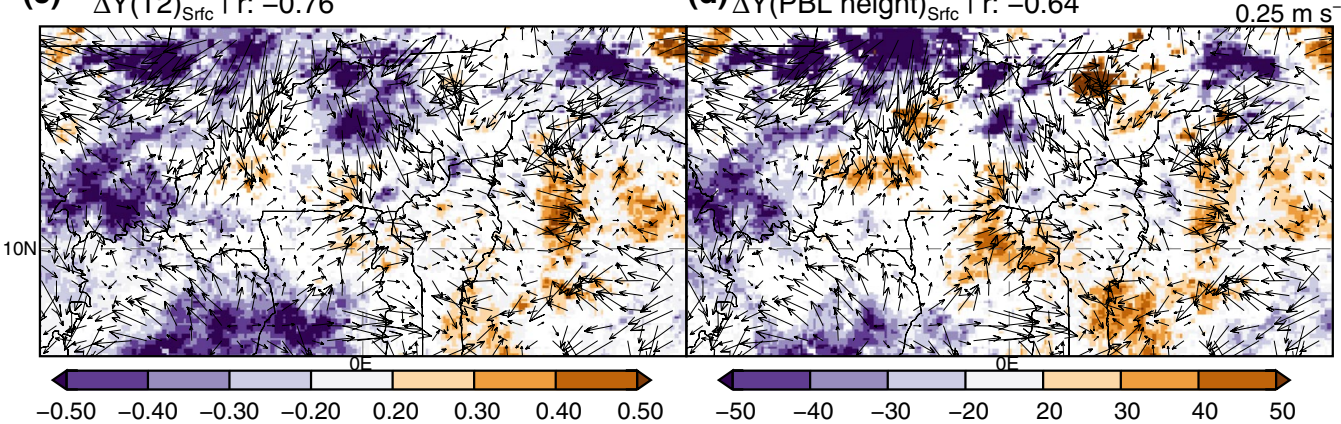

(e)

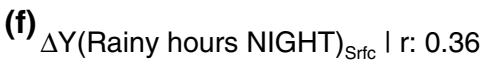

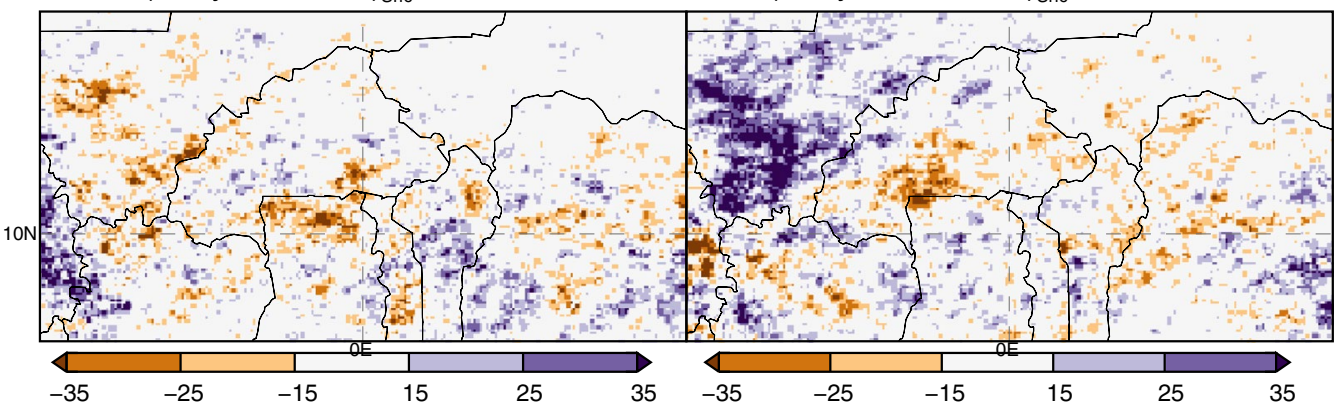

(g) Maximum $\mathrm{PCP}_{\text {Dyn }}$ shift I $62 \%$

(h) ${ }_{\Delta \mathrm{Y}(\mathrm{PCP})_{\mathrm{Srfc}}} \mid \mathrm{r}: 0.054$

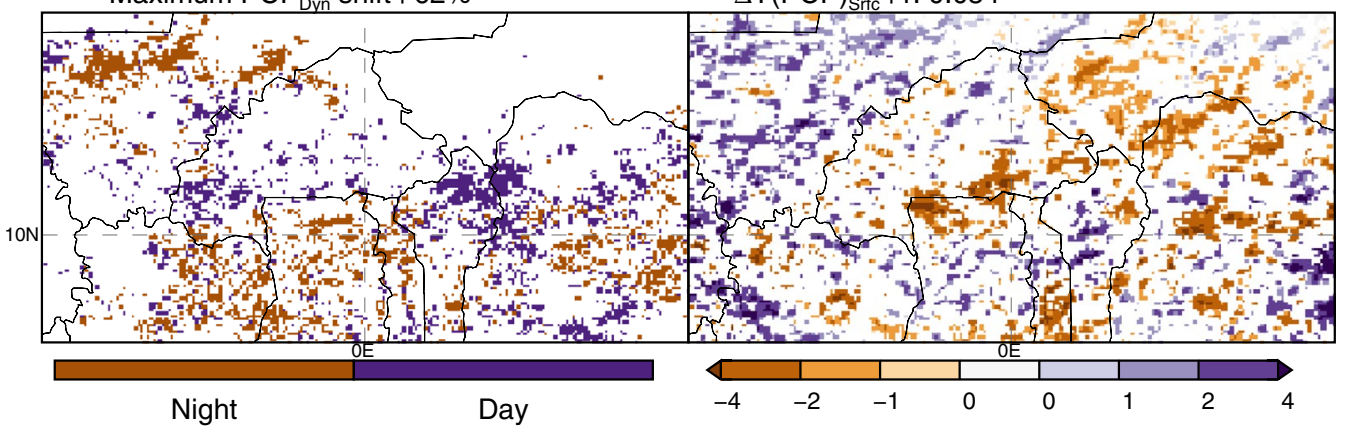

Fig. 10 Maps for Aug-Sep: a $\Delta \mathrm{Y}(\mathrm{CAPE})_{\mathrm{Srfc}}\left(\mathrm{J} \mathrm{kg}^{-1}\right)$, b $\Delta \mathrm{Y}_{\mathrm{Srfc}}$ for the number of daytime hours in which the PBL height reaches the lifted condensation level (LCL). Stripes in $\mathbf{a}, \mathbf{b}$ mark insignificant changes of CAPE. c, d $\Delta \mathrm{Y}_{\mathrm{Srfc}}$ for $2 \mathrm{~m}$ temperature (T2, K), PBL height $(\mathrm{m})$ and $10 \mathrm{~m}$ wind vectors $\left(\mathrm{m} \mathrm{s}^{-1}\right)$. (e,f) $\Delta \mathrm{Y}_{\text {Srfc }}$ of rainy hours during the day (0700-1800 UTC)/ night $\left(\geq 1 \mathrm{~mm} \mathrm{~h}^{-1}\right)$, g pixels showing a shift of the precipitation maximum from night to day ("Day") or vice-versa ("Night") between 2009 and 2010 in DYN. No shift or a shift corresponding to CLIM are ignored. The percentage is the portion of pixels where a shift to "Day" ("Night") falls together with a negative (positive) change in vegetation fraction (VF) (h) $\Delta \mathrm{Y}_{\text {Srfc }}$ precipitation (PCP, mm day ${ }^{-1}$ ). Only significant $\Delta \mathrm{Y}_{\text {Srfc }}$ are shown. Spatial correlations (r) are with respect to $\Delta \mathrm{Y}(\mathrm{VF})_{\text {Srfe }}$ (cf. Fig. 8a) and are significant $(P \leq 0.01)$ except for $(\mathrm{h})$ 
Due to the existence of these positive and negative VFPCP feedbacks, especially in the Sudanian zone, there is no correlation for $\Delta \mathrm{Y}(\mathrm{PCP})_{\mathrm{Srfc}}$ in Fig. 10h. On average, the significant local changes reach $\pm 2.2 \mathrm{~mm} \mathrm{day}^{-1}$, for which the sign largely depends on whether the daytime or the nighttime VF-PCP feedback dominates.

\subsection{Observed and modelled feedback on precipitation}

The previous section showed that an atmospheric signal that is related to the interannual vegetation changes can be extracted not only for variables that characterize the state of the PBL, but also for rainfall. The question remains whether the simulated vegetation-driven adjustments are realistic and if so, whether the signal is detectable in the observations for which the dominating large-scale signal cannot be removed i.e. it is not possible to determine a $\Delta \mathrm{Y}_{\text {Srfc. }}$.

Nevertheless, the daily PCP statistics in Fig. 11 for 2009 and 2010 show a small but consistent increase of the Heidke skill score (HSS) for DYN for thresholds below $40 \mathrm{~mm}^{\text {day }}{ }^{-1}$ during both years. The HSS measures the improvement of the forecast skill over a random forecast and is computed for different thresholds over the whole study domain for every grid cell and every day. The HSS for both WRF cases is relatively low, but it should be kept in mind that WRF is only forced at the domain boundaries (cf. Sect. 2.1) and is otherwise allowed to create its own weather. Reasons why these free running simulations can perform better in capturing precipitating systems in space and time than a random process (HSS $>0$ ) must therefore be related to strong atmospheric boundary conditions (e.g. atmospheric waves travelling through the model domain) or, to a lesser extent and only in the case of DYN, by the introduced land surface information. Since there is no substantial difference between DYN and CLIM in the frequency distribution or in the ability to capture daily mean PCP, the slightly higher HSS for DYN most likely stems from a surface-driven improvement in the spatio-temporal localisation of precipitating systems.
Fig. 11 Aug-Sep precipitation (top) time series, (middle) Heidke skill score (HSS) and (bottom) precipitation frequency for daily values in a 2009 and b 2010 for DYN and CLIM with respect to the reference datasets (REF) TRMM, RFE and CMORPH over the study domain. HSS is computed as the average $\mathrm{HSS}_{\text {Mean }}$ per threshold from the complete spatiotemporal array with respect to all three references. $r^{2}$ is with respect to the reference dataset average $\mathrm{REF}_{\text {Mean }}$ (a) …. REF DYN $I r^{2}: 0.43$
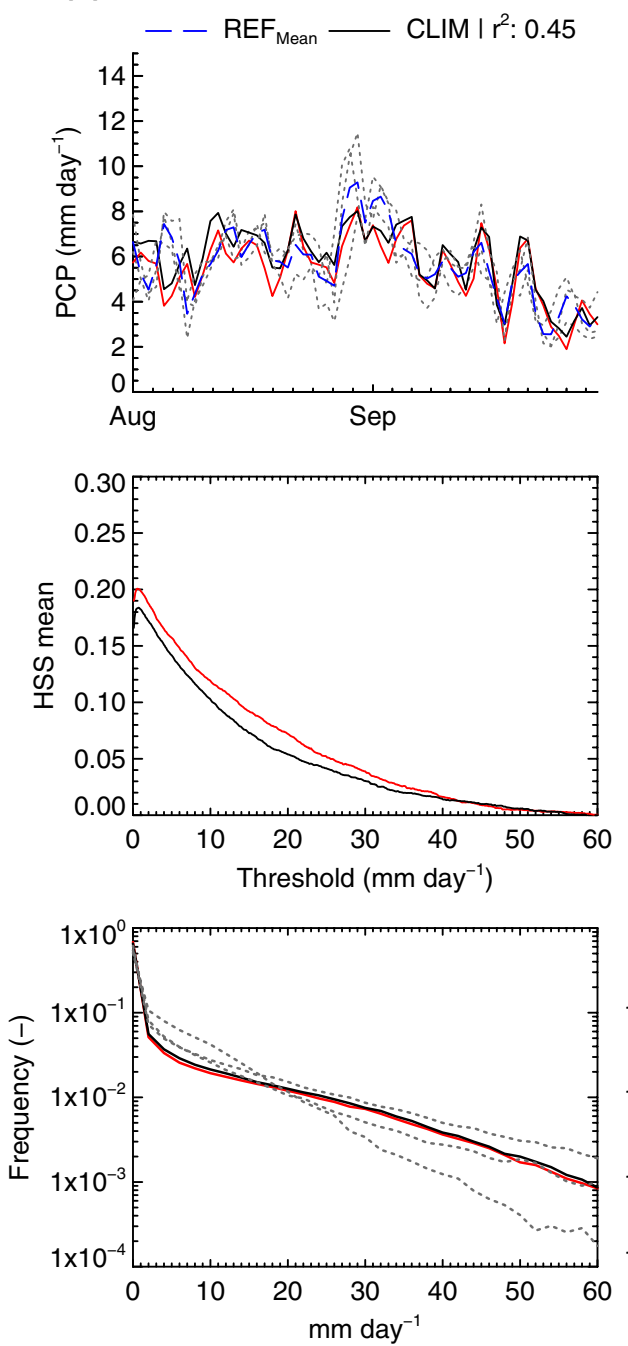
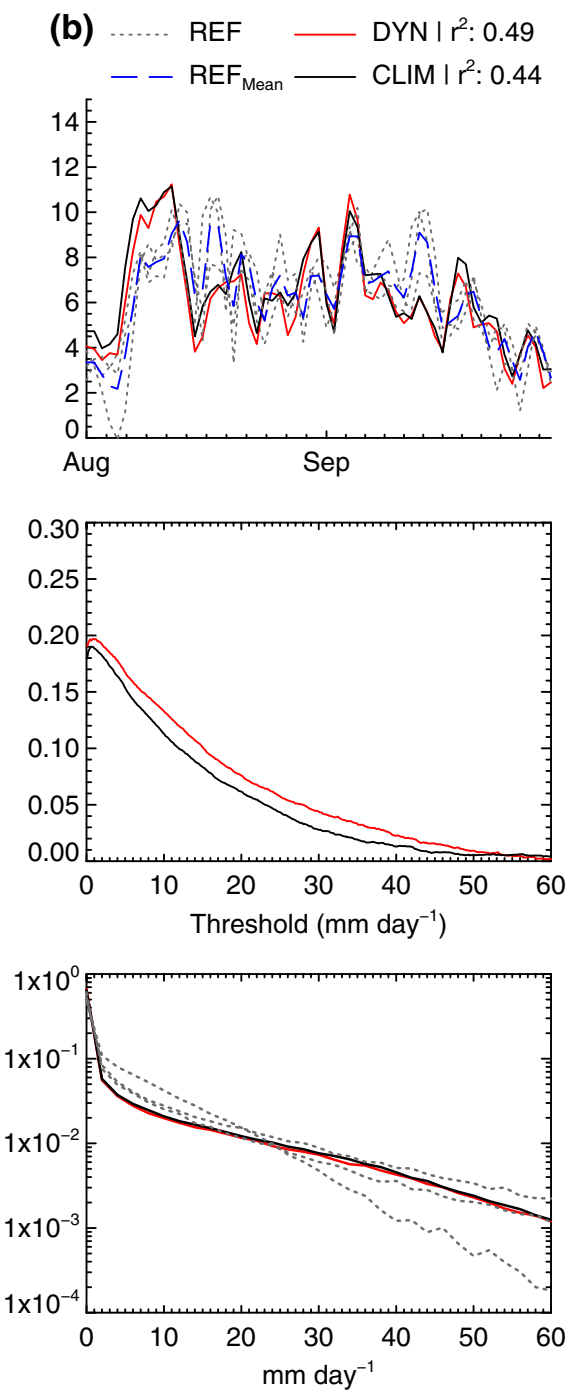
To test the impact of changes in VF, Fig. 12 shows the strength of the relationship between $\Delta \mathrm{Y}(\mathrm{VF})_{\mathrm{Dyn}}$ and the $\triangle \mathrm{Y}(\mathrm{PCP})$ of DYN, CLIM and the reference datasets. We are only including pixels where $\Delta \mathrm{Y}(\mathrm{PCP})_{\text {Srfc is significant (cf. }}$ Fig. 10h) presuming that these regions have the potential for considerable land-atmosphere feedbacks (sufficient surface change) and to therefore strengthen the surface signal.

The difficulty here is to extract a vegetation-precipitation feedback from the obvious precipitation-vegetation forcing. We rely on the idea that the correlation between $\Delta \mathrm{Y}(\mathrm{PCP})_{\mathrm{Clim}}$ and $\Delta \mathrm{Y}(\mathrm{VF})_{\text {Dyn }}$ represents the baseline relationship between large-scale driven PCP changes and resulting VF patterns. Any correlation surplus (strengthened relationship) for DYN or the reference datasets in comparison to CLIM should be an indicator for an effect of the surface on the PCP patterns.

This approach works well in the Sahel (Fig. 12a) where we find a $\Delta \mathrm{Y}(\mathrm{VF})_{\text {Dyn }}-\Delta \mathrm{Y}(\mathrm{PCP})_{\text {Dyn }}$ correlation of 0.23 corresponding to correlations between 0.16 and 0.23 for the reference datasets. This relationship cannot be explained by large-scale interannual variability alone as illustrated by a very small correlation of 0.08 for $\Delta \mathrm{Y}(\mathrm{PCP})_{\text {Clim }}$ which confirms an improved spatial PCP distribution for DYN.
The correlations of the reference datasets show that $\Delta \mathrm{Y}(\mathrm{VF})_{\text {Dyn }}$ explains at most $5 \%$ spatial variance $\left(\mathrm{r}^{2}=0.23^{2}=0.05\right.$ for RFE $)$ of the average PCP changes between Aug-Sep 2009 and 2010. Note that this is valid only for the regions where a potentially strong feedback was detected.

In the Sudanian zone, there is no correlation for the WRF simulations but small positive correlations for the reference datasets most likely due to the precipitation-vegetation forcing (Fig. 12b). WRF has difficulties to capture the observed patterns of large-scale driven PCP differences in that region, which might explain the complete lack of a correlation with $\Delta \mathrm{Y}(\mathrm{VF})_{\text {Dyn }}$. Ultimately, the strong predominance of the large-scale monsoon dynamics in determining interannual precipitation differences in the Sudanian zone seems to inhibit any signal detection directly from $\Delta \mathrm{Y}$.

\section{Discussion and conclusions}

This study examines the feedback of land surface and atmospheric variables in response to year-to-year vegetation changes between two consecutive years $(2009,2010)$
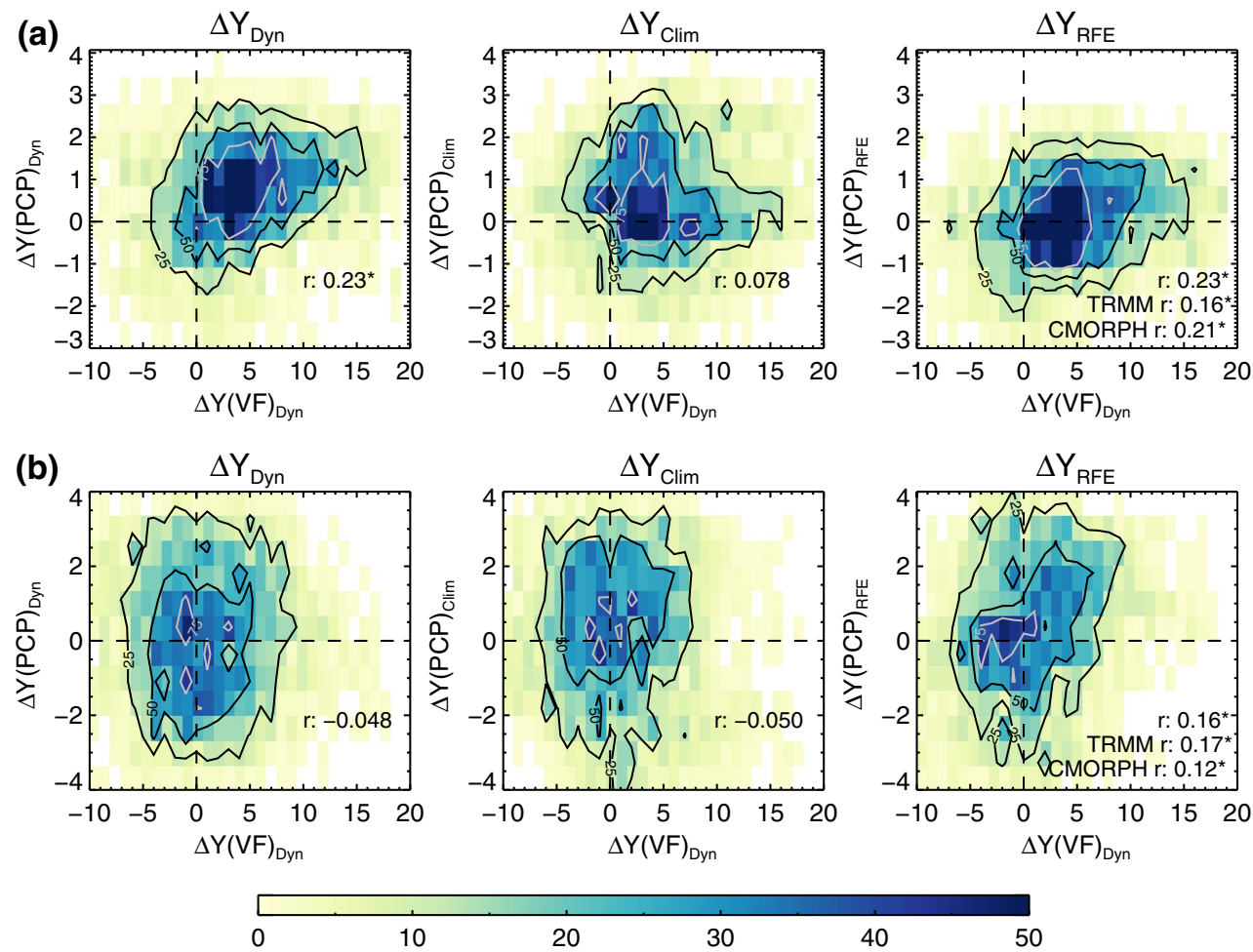

10

20

30

40

50

Fig. 12 Aug-Sep density scatterplots between the $\Delta Y$ for the dynamical vegetation fraction $\left(\mathrm{VF}_{\mathrm{Dyn}}\right)$ and average precipitation (PCP) for DYN, CLIM and the reference dataset RFE $\mathbf{a}$ in the Sahel, b in the Sudanian zone. Only regions where $\Delta \mathrm{Y}_{\text {Srfc }}$ precipitation is significant (cf. Fig. 10h) are included in the spatial correla- tion (r). Significant $\mathrm{r}$ are marked with a star and are also displayed for TRMM and CMORPH for comparison. Contours indicate the 75th, 50th and 25th percentile of the maximum density. The binsize is $0.75 \mathrm{~mm} \mathrm{day}^{-1}$ for PCP and $1 \%$ for VF 
during the West African monsoon in August and September with the aim to (1) assess whether these natural changes have an effect on the rainfall distribution during the WAM and (2) to investigate whether the implementation of satellite-derived surface parameters improves the representation of surface variables and rainfall in the Weather Research and Forecasting (WRF) model.

Satellite-derived dynamical information for albedo, leaf area index and vegetation fraction were implemented into the WRF model. A control case uses default surface parameters that follow a climatological annual cycle during both years and therefore represents the large-scale driven changes.

We find that interannual changes of total precipitation amounts at continental scale are relatively insensitive to natural interannual vegetation changes, which confirms previous realistic feedback studies (e.g. Lauwaet et al. 2009; Taylor et al. 2002).

However, at regional scale, we detect a significant response of surface temperatures and turbulent surface fluxes to changing vegetation patterns that is especially pronounced at the outskirts of the monsoon rainband. Over positive vegetation changes, we find shallower and moister planetary boundary layers (PBL) related to lower surface temperatures and higher latent heat fluxes. In these regions, the number of daytime rainy hours shows a decrease while it is vice-versa over areas with negative vegetation changes. Positive vegetation changes foster divergence that decreases the potential for initiation of deep convection in the afternoon, which Garcia-Carreras et al. (2011) attribute to the formation of a stabilizing capping layer above the PBL. Over the warmer areas with negative vegetation changes, on the other hand, moist air converges and stronger thermals may more easily break through the stable layer, which ultimately favours deep convection. Comparable mechanisms were also suggested in observational studies on the development of convective clouds elsewhere, e.g. USA and Amazonia (Rabin et al. 1990; Chagnon et al. 2004). Wang et al. (2009) identify mesoscale circulations in the Amazon from forested to deforested patches as an important lifting mechanism that leads to frequent initiation of convection over deforested regions while there was no deep convection over uniform forest in spite of sufficient CAPE.

Our results show an opposite signal for nighttime precipitation, with rain falling more often over areas with increased vegetation cover. This positive feedback might be related to a strengthening of mature MCSs that were triggered in the afternoon (Mathon and Laurent 2001) and that profit energetically from the uplift of moist boundary layer air (Clark et al. 2003; Alonge et al. 2007). A global study by Taylor et al. (2012) based on remote sensing data likewise showed that daytime (afternoon) precipitation falls preferentially over drier soils, while during the night, the picture is reversed with precipitation being more likely over wetter soils. They also evaluated the behaviour of six global climate models, which showed opposite results most likely related to the model's inability to take into account small scale boundary layer processes and to shortcomings of the convective parameterisations. Here, we show that the atmospheric model indeed is able to reproduce these observed land-atmosphere interactions when mesoscale features can be resolved explicitly and no convective parameterisation is used. This denotes that the explicit treatment of convection could be a crucial point for any model-based land-atmosphere interaction study.

Furthermore, we suggest that vegetation patterns essentially foster similar atmospheric processes as were identified for soil moisture with positive as well as negative feedbacks (e.g. Emori 1998; Kunstmann and Jung 2007; Findell and Eltahir 2003; Hohenegger et al. 2009; Taylor et al. 2012; Gantner and Kalthoff 2010), which we find to be directly connected to the time of day and most likely to the typical lifecycle of mesoscale convective systems during the WAM (initiation during the afternoon versus westward propagation during the night).

However, different from the soil moisture-atmosphere feedback (e.g. Dirmeyer 2011), we find that, at the seasonal time scale, the vegetation-atmosphere feedback is driven by spatial heterogeneity rather than temporal variability, shown by significant spatial correlation between vegetation patterns and atmospheric response over an aggregated time period of two months during the peak monsoon. At the same time, we identify natural interannual vegetation changes to be sufficient to change the preference for maximum precipitation during daytime in a region to a nighttime preference from one year to the next, highlighting the importance of temporal vegetation change at this longer time scale.

Interestingly, we also detect the vegetation-atmosphere feedback described above in the Sudanian zone. Since soil moisture is plentiful and the monsoon dynamics are strong during August-September in this region, it is not considered to be prone to land-atmosphere interactions, as was diagnosed from studies focussing on soil moisture (e.g. Van der Hurk and van Meijgaard 2010; Xue et al. 2012). However, related to the long-lasting nature of vegetation patterns, the atmosphere may adapt to the vegetation forcing whenever the atmospheric conditions are favourable, making vegetation presumably the more important factor in that region. Kohler et al. (2010) correspondingly found that during the mature monsoon stage July-August, vegetation instead of soil moisture becomes the dominating factor for surface processes impacting the boundary layer. We therefore want to emphasize that land-atmosphere coupling can be identified based on a covariance of surface and atmospheric variables at temporal scale (e.g. soil moisture variance at a point, Dirmeyer 2011) 
or at spatial scale (e.g. persistent vegetation patterns). In our case, the latter definition suggests a feedback even under conditions where soil moisture is not limited.

However, for observed rainfall, the feedback was only traceable in the Sahel where a shift of a convective system can be a matter of "any or none" precipitation for that location. Since it is impossible to remove the large-scale signal from observational data, the vegetation-rainfall feedback must be a considerable contribution to the largescale driven precipitation patterns in order to be detectable, which is not given in the core of the monsoon rainband. Hence, the validity of the modelled feedback in this region remains uncertain.

We therefore conclude that, on interannual time scales, the implementation of satellite-derived dynamical vegetation into an atmospheric model predominantly improves the simulations at the edges of the monsoon rainband. Future studies should concentrate on the dry and premonsoon season, when the synoptic forcing and moisture advection are weaker and the impact of prevailing vegetation patterns could quantitatively be more important. Furthermore, we would like to mention that there is an imbalance of observational studies addressing the impact of soil moisture and vegetation patterns in West Africa, with the latter receiving much less attention. The development of methods to extract signals of vegetation-atmosphere feedbacks from measurements or satellite data will greatly help to validate modelled feedbacks.

Acknowledgments This work has been funded by the German Federal Ministry of Education and Research (BMBF) through the West African Science Service Center on Climate Change and Adapted Land Use (WASCAL). We would like to thank the German Climate Computing Center (DKRZ) for providing the computing facilities. The CPC soil moisture data and the University of Delaware gridded surface air temperature dataset were provided by the NOAA/OAR/ESRL PSD, Boulder, Colorado, USA (http://www.esrl.noaa.gov/psd/). We furthermore thank the international WRF community for the development and support of the WRF model. All analyses were done using IDL with the graphics based on the Coyote graphics library developed by David Fanning.

Open Access This article is distributed under the terms of the Creative Commons Attribution 4.0 International License (http://creativecommons.org/licenses/by/4.0/), which permits unrestricted use, distribution, and reproduction in any medium, provided you give appropriate credit to the original author(s) and the source, provide a link to the Creative Commons license, and indicate if changes were made.

\section{References}

Albergel C, Dorigo W, Reichle R, Balsamo G, de Rosnay P, MuñozSabater J, Isaksen L, de Jeu R, Wagner W (2013) Skill and global trend analysis of soil moisture from reanalyses and microwave remote sensing. J Hydrometeorol 14:1259-1277. doi:10.1175/ JHM-D-12-0161.1
Alo CA, Wang G (2010) Role of dynamic vegetation in regional climate predictions over western Africa. Clim Dyn 35(5):907-922. doi:10.1007/s00382-010-0744-Z

Alonge CJ, Mohr KI, Tao W-K (2007) Numerical studies of wet versus dry soil regimes in the West African Sahel. J Hydrometeorol 8(1):102-116. ISBN 1525-755X. doi:10.1175/JHM559.1. http://journals.ametsoc.org/doi/abs/10.1175/JHM559.1

Anthes RA (1984) Enhancement of convective precipitation by mesoscale variations in vegetative covering in semiarid regions. $J$ Clim Appl Meteorol 23:541-554

Balsamo G, Albergel C, Beljaars A, Boussetta S, Brun E, Cloke H, Dee D, Dutra E, Muñoz-Sabater J, Pappenberger F, de Rosnay P, Stockdale T, Vitart F (2015) ERA-Interim/land: a global land surface reanalysis data set. Hydrol Earth Syst Sci 19(1):389-407. doi:10.5194/hess-19-389-2015

Baret F, Weiss M (2010) Towards an operational GMES land monitoring core service-BioPar methods compendium-LAI, FAPAR, F COVER NDVI. Geoland 2

Baret F, Weiss M (2014) Gio global land component-lot I operation of the global land component. Technical report

Berg A, Lintner BR, Findell K, Seneviratne SI, van den Hurk B, Ducharne A, Chéruy F, Hagemann S, Lawrence DM, Malyshev S, Meier A, Gentine P (2015) Interannual coupling between summertime surface temperature and precipitation over land: processes and implications for climate change. J Clim 28(3):13081328. doi:10.1175/JCLI-D-14-00324.1

Camacho F, Cernicharo J (2015) Gio global land component-lot I operation of the global land component. Technical report

Camacho F, Sánchez J (2015) Gio global land component-lot I operation of the global land component. Technical report

Camberlin P, Martiny N, Philippon N, Richard Y (2007) Determinants of the interannual relationships between remote sensed photosynthetic activity and rainfall in tropical Africa. Remote Sens Environ 106:199-216. doi:10.1016/j.rse.2006.08.009

Chagnon FJF, Bras RL, Wang J (2004) Climatic shift in patterns of shallow clouds over the Amazon. Geophys Res Lett. doi:10.102 9/2004GL021188

Chen F, Dudhia J (2001) Coupling an advanced land surface-hydrology model with the Penn State-NCAR MM5 modeling system. Part I: Model implementation and sensitivity. Mon Weather Rev 129(4):569-585

Clark DB, Taylor CM, Thorpe AJ, Harding RJ, Nicholls ME (2003) The influence of spatial variability of boundary-layer moisture on tropical continental squall lines. Q J R Meteorol Soc 129(589):1101-1121. doi:10.1256/qj.02.122

Clark DB, Taylor CM (2004) Feedback between the land surface and rainfall at convective length scales. J Hydrometeorol 5:625-639

Cook KH (1999) Generation of the African easterly jet and its role in determining West African precipitation. J Clim 12:1165-1184

Csiszar I, Gutman G (1999) Mapping global land surface albedo from NOAA AVHRR. J Geophys Res 104(1998):6215-6228

Dee DP, Uppala SM, Simmons AJ, Berrisford P, Poli P, Kobayashi S, Andrae U, Balmaseda Ma, Balsamo G, Bauer P, Bechtold P, Beljaars CM (2011) The ERA-Interim reanalysis: configuration and performance of the data assimilation system. Q J R Meteorol Soc 137(656):553-597. doi:10.1002/qj.828

Dirmeyer PA (2011) The terrestrial segment of soil moisture-climate coupling. Geophys Res Lett. doi:10.1029/2011GL048268

Dudhia J (1989) Numerical study of convection observed during the winter monsoon experiment using a mesoscale two-dimensional model. J Atmos Sci 46:3077-3107

Eltahir E (1998) A soil moisture-rainfall feedback mechanism 1. Theory and observations. Water Resour Res 34(4):765-776

Emori S (1998) The interaction of cumulus convection with soil moisture distribution: an idealized simulation. J Geophys Res 103(D8):8873-8884 
Findell K, Eltahir E (2003) Atmospheric controls on soil moistureboundary layer interactions. Part I: framework development. J Hydrometeorol 4:552-569

Friedl Ma, Sulla-Menashe D, Tan B, Schneider A, Ramankutty N, Sibley A, Huang X (2010) MODIS Collection 5 global land cover: algorithm refinements and characterization of new datasets. Remote Sens Environ 114(1):168-182. doi:10.1016/j. rse.2009.08.016

Gantner L, Kalthoff N (2010) Sensitivity of a modelled life cycle of a mesoscale convective system to soil conditions over West Africa. Q J R Meteorol Soc 136(S1):471-482. doi:10.1002/qj.425

Garcia-Carreras L, Parker DJ, Marsham JH (2011) What is the mechanism for the modification of convective cloud distributions by land surface induced flows? J Atmos Sci 68(3):619-634. doi:10. 1175/2010JAS3604.1

Gessner U, Niklaus M, Kuenzer C, Dech S (2013) Intercomparison of leaf area index products for a gradient of sub-humid to arid environments in West Africa. Remote Sens 5:1235-1257

Gessner U, Machwitz M, Esch T, Tillack A, Naeimi V, Kuenzer C, Dech S (2015) Multi-sensor mapping of West African land cover using MODIS, ASAR and TanDEM-X/TerraSAR-X data. Remote Sens Environ 164:282-297. doi:10.1016/j.rse.2015.03.029

Gutman G, Ignatov A (1998) The derivation of the green vegetation fraction from NOAA/AVHRR data for use in numerical weather prediction models. Int J Remote Sens 19(8):1533-1543

Hagos S, Leung LR, Xue Y, Boone A, de Sales F, Neupane N, Huang M, Yoon J-H (2014) Assessment of uncertainties in the response of the African monsoon precipitation to land use change simulated by a regional model. Clim Dyn 43(9-10):2765-2775. doi:10.1007/s00382-014-2092-x

Hansen MC, Potapov PV, Moore R, Hancher M, Turubanova SA, Tyukavina A, Thau D, Stehman SV (2013) High-resolution global maps of 21 st-century forest cover change. Science 342(6160):850-853

Harris I, Jones PD, Osborn TJ, Lister DH (2013) Updated high-resolution grids of monthly climatic observations. Int $\mathrm{J}$ Climatol. doi: $10.1002 /$ joc. 3711

Hohenegger C, Brockhaus P, Bretherton CS, Schär C (2009) The soil moisture-precipitation feedback in simulations with explicit and parameterized convection. J Clim 22(19):5003-5020. doi:1 0.1175/2009JCLI2604.1

Hollmann R, Merchant CJ, Saunders R, Downy C, Buchwitz M, Cazenave A, Chuvieco E, Defourny P, de Leeuw G, Forsberg R, Holzer-Popp T, Paul F, Sandven S, Sathyendranath S, van Roozendael M, Wagner W (2013) The ESA climate change initiative: satellite data records for essential climate variables. Bull Am Meteorol Soc 94(10):1541-1552. doi:10.1175/ BAMS-D-11-00254.1

Hong S, Noh Y, Dudhia J (2006) A new vertical diffusion package with an explicit treatment of entrainment processes. Mon weather Rev 134:2318-2341

Huffman G, Adler R, Rudolf B, Schneider U, Keehn P (1995) Global precipitation estimates based on a technique for combining satellite-based estimates, rain gauge analysis, and NWP model precipitation information. J Clim 8:1284-1295

Huffman G, Adler R, Arkin P, Chang A, Ferraro R, Gruber A, Schneider U, Janowiak J, McNab A, Rudolph B (1997) The global precipitation climatology project (GPCP) combined precipitation dataset. Bull Am Meteorol Soc 78:5-20

Joyce RJ, Janowiak EJ, Arkin PA, Xie P (2004) CMORPH: a method that produces global precipitation estimates from passive microwave and infrared data at high spatial and temporal resolution. J Hydrometeorol 5:487-503

Jung M, Reichstein M, Margolis HA, Cescatti A, Richardson AD, Arain MA, Arneth A, Bernhofer C, Bonal D (2011) Global patterns of land-atmosphere fluxes of carbon dioxide, latent heat, and sensible heat derived from eddy covariance, satellite, and meteorological observations. J Geophys Res 116:00-07. doi:10.1029/2010JG001566

Klein C, Heinzeller D, Bliefernicht J, Kunstmann H (2015) Variability of West African monsoon patterns generated by a WRF multi-physics ensemble. Clim Dyn. doi:10.1007/ s00382-015-2505-5

Kohler M, Kalthoff N, Kottmeier C (2010) The impact of soil moisture modifications on CBL characteristics in West Africa: a case-study from the AMMA campaign. Q J R Meteorol Soc 136(S1):442-455. doi:10.1002/qj.430

Koster R, Dirmeyer P, Guo Z, Bonan G, Chan E, Cox P, Gordon C, Kanae S, Kowalczyk E, Lawrence D, Liu P, Lu C-H, Malyshev S, McAvaney B, Mitchell K, Mocko D, Oki T, Oleson K, Pitman A, Sud Y-C, Taylor CM, Verseghy D, Vasic R, Xue Y, Yamada $\mathrm{T}$ (2004) Regions of strong coupling between soil moisture and precipitation. Science 305(5687):1138-1140

Kucharski F, Zeng N, Kalnay E (2012) A further assessment of vegetation feedback on decadal Sahel rainfall variability. Clim Dyn 40(5-6):1453-1466. doi:10.1007/s00382-012-1397-x

Kumar A, Chen F, Barlage M, Ek MB, Niyogi D (2014) Assessing impacts of integrating MODIS vegetation data in the weather research and forecasting (WRF) model coupled to two different canopy-resistance approaches. J Appl Meteorol Climatol 53:1362-1380. doi:10.1175/JAMC-D-13-0247.1

Kunstmann H (2008) Effective SVAT-model parameters through inverse stochastic modelling and second-order first moment propagation. J Hydrol 348(1-2):13-26. doi:10.1016/j.jhydrol.2007.09.032

Kunstmann H, Jung G (2007) Influence of soil-moisture and land use change on precipitation in the Volta Basin of West Africa. Int $\mathrm{J}$ River Basin Manag 5(2):1-8

Lauwaet D, van Lipzig NPM, De Ridder K (2009) The effect of vegetation changes on precipitation and Mesoscale convective systems in the Sahel. Clim Dyn 33(4):521-534. doi:10.1007/s00382-009-0539-2

Lawrimore J, Menne M, Gleason B, Williams C, Wuertz D, Vose R, Rennie J (2011) An overview of the global historical climatology network monthly mean temperature data set, version 3. Geophys Res Lett 116:19121. doi:10.1029/2011JD016187

Legates DR, Willmott CJ (1990) Mean seasonal and spatial variability in global surface air temperature. Theor Appl Climatol 41(12):11-21. doi:10.1007/BF00866198

Li W, Xue Y, Poccard-Leclercq I (2007) Numerical investigation of the impact of vegetation indices on the variability of West African summer monsoon. J Meteorol Soc Jpn 85A:363-383

Lin YL, Farley RD, Orville HD (1983) Bulk parameterization of the snow field in a cloud model. J Appl Meteorol 22:1065-1092

Lohou F, Kergoat L, Guichard F, Boone a, Cappelaere B, Cohard J-M, Demarty J, Galle S, Grippa M, Peugeot C, Ramier D, Taylor CM, Timouk F (2014) Surface response to rain events throughout the West African monsoon. Atmos Chem Phys 14(8):38833898. doi:10.5194/acp-14-3883-2014. http://www.atmoschemphys.net/14/3883/2014/

LP DAAC (2014) Modis product Mcd43b3. Technical report, NASA EOSDIS Land Processes Distributed Active Archive Center, , USGS/Earth Resources Observation and Science (EROS) Center, Sioux Falls, South Dakota

LSA SAF (2013) Product user manual vegetation parameters (vega). Technical report. The EUMETSAT satellite application facility on land surface analysis

Marsham JH, Dixon NS, Garcia-carreras L, Lister GMS, Parker DJ, Knippertz P, Birch CE (2013) The role of moist convection in the West African monsoon system : Insights from continental-scale convection-permitting simulations. Geophys Res Lett 40:18431849. doi:10.1002/grl.50347

Mathon V, Laurent H (2001) Life cycle of Sahelian mesoscale convective cloud systems. Q J R Meteorol Soc 127:377-406 
Mayaux P, Bartholomé E, Fritz S, Belward A (2004) A new landcover map of Africa for the year 2000. J Biogeogr 31(6):861877. doi:10.1111/j.1365-2699.2004.01073.x

Nicholson SE (2013) The West African Sahel: a review of recent studies on the rainfall regime and its interannual variability. ISRN Meteorol 2013:1-32. doi:10.1155/2013/453521

NOAA CPC (2013) NOAA CPC African rainfall estimates. http:// iridl.ldeo.columbia.edu/SOURCES/.NOAA/.NCEP/.CPC/. FEWS/

Rabin R, Stadler S, Wetzel P, Stensrud D, Gregory M (1990) Observed Effects of Landscape Variability on Convective Clouds. Bull Am Meteorol Soc 71(3):272-280

Redelsperger J-L, Thorncroft CD, Diedhiou A, Lebel T, Parker DJ, Polcher J (2006) African monsoon multidisciplinary analysis. Bull Am Meteorol Soc. doi:10.1175/BAMS-87-12-1739

Reichle R, Koster RD, de Lannoy GJ, Forman BA, Liu Q, Mahanama SP, Touré A (2011) Assessment and enhancement of MERRA land surface hydrology estimates. J Clim 24:6322-6338. doi:10.1175/JCLI-D-10-05033.1

Seneviratne SI, Corti T, Davin EL, Hirschi M, Jaeger EB, Lehner I, Orlowsky B, Teuling AJ (2010) Investigating soil moisture-climate interactions in a changing climate: a review. Earth Sci Rev 99(3-4):125-161. doi:10.1016/j.earscirev.2010.02.004

Skamarock WC, Klemp JB, Dudhia J, Gill DO, Barker DM, Duda MG, Huang X, Wang W, Powers JG, Division MM (2008) A description of the advanced research WRF version 3. Technical report, NCAR, Boulder, Colorado, USA

Taylor CM (2008) Intraseasonal land-atmosphere coupling in the West African monsoon. J Clim 21(24):6636-6648. doi:10.1175/2008J CLI2475.1

Taylor CM, Lambin EF, Stephenne N, Harding RJ, Essery RLH (2002) The influence of land use change on climate in the Sahel. J Clim 15:3615-3629

Taylor CM, Harris PP, Parker DJ (2010) Impact of soil moisture on the development of a Sahelian mesoscale convective system: a case-study from the AMMA special observing period. Q J R Meteorol Soc 136(S1):456-470. doi:10.1002/qj.465

Taylor CM, Gounou A, Guichard F, Harris PP, Ellis RJ, Couvreux F, Kauwe MD (2011a) Frequency of Sahelian storm initiation enhanced over mesoscale soil-moisture patterns. Nat Geosci 4(7):430-433. doi:10.1038/ngeo1173

Taylor CM, Parker DJ, Kalthoff N, Gaertner MA, Philippon N, Bastin S, Harris PP, Boone A, Guichard F, Agusti-Panareda A (2011) New perspectives on land-atmosphere feedbacks from the African Monsoon Multidisciplinary Analysis. Atmos Sci Lett 12(1):38-44. doi:10.1002/asl.336

Taylor CM, de Jeu RAM, Guichard F, Harris PP, Dorigo Wa (2012) Afternoon rain more likely over drier soils. Nature 489(7416):423-426. doi:10.1038/nature11377

Van Den Dool H, Huang J, Fan Y (2003) Performance and analysis of the constructed analogue method applied to US soil moisture applied over 1981-2001. J Geophys Res 108:1-16

Van der Hurk BJ, van Meijgaard E (2010) Diagnosing land-atmosphere interaction from a regional climate model simulation over West Africa. Am Meteorol Soc 11:467-481. doi:10.1175/2009 JHM1173.1

Wang G, Eltahir EAB (2000) Biosphere-atmosphere interactions over West Africa. I: development and validation of a coupled dynamic model. Q J R Meteorol Soc 126:1239-1260

Wang J, Chagnon F, Williams ER, Betts AK, Renno NO, Machado LAT, Bisht G, Knox R, Bras RL (2009) Impact of deforestation in the Amazon basin on cloud climatology. Proc Natl Acad Sci USA. doi:10.1073/pnas.0810156106

William H, Flannery B, Teukolsky S, Vetterling W (1992) 14.8 Savitzky-Golay smoothing filters. In: Numerical recipes in C: the art of scientific computing, 2nd edn. Cambridge University Press, Cambridge, pp 650-655

Xue Y, Boone A, Taylor CM (2012) Review of recent developments and the future prospective in West African atmosphere/land interaction studies. Int J Geophys 2012:1-12. doi:10.1155/2012/748921

Zhang D, Anthes RA (1982) A high-resolution model of the planetary boundary layer-sensitivity tests and comparisons with sesame-79 data. J Appl Meteorol 21:1594-1609

Zheng X, Eltahir EAB (1998) The role of vegetation in the dynamics of West African monsoons. J Clim 11(8):2078-2096. doi:10.1175/1520-0442-11.8.2078 